\title{
Detection and removal of microplastics in wastewater: evolution and impact
}

\author{
Thuhin K. Dey ${ }^{1} \cdot$ Md. Elias Uddin ${ }^{1} \cdot$ Mamun Jamal $^{2}$ (D) \\ Received: 18 August 2020 / Accepted: 9 February 2021 / Published online: 25 February 2021 \\ (C) The Author(s), under exclusive licence to Springer-Verlag GmbH, DE part of Springer Nature 2021
}

\begin{abstract}
The pervasiveness of microplastics in aquatic ecosystems has become a major environmental issue in recent years. The gradual dumping of plastic wastes, inadequate standard detection methods with specific removal techniques, and slow disposal rate of microplastics make it ubiquitous in the environment. Evidence shows that microplastics act as a potential vector by adsorbing different heavy metals, pathogens, and other chemical additives widely used in different raw plastic production. Microplastics are ingested by aquatic creatures such as fish and different crustaceans, and finally, people ingest them at the tertiary level of the food chain. This phenomenon is responsible for blocking the digestion tracts, disturbing the digestive behavior, finally decreasing the reproductive growth of entire living organisms. Because of these consequences, microplastics have become an increasing concern as a newly emerging potential threat, and therefore, the control of microplastics in aquatic media is required. This paper provides a critical analysis of existing and newly developed methods for detecting and separating microplastics from discharged wastewater, which are the ultimate challenges in the microplastic treatment systems. A critical study on the effect of microplastics on aquatic organisms and human health is also discussed. Thus, this analysis provides a complete understanding of entire strategies for detecting and removing microplastics and their associated issues to ensure a waste discharge standard to minimize the ultimate potential impact in aquatic environments.
\end{abstract}

Keywords Plastics $\cdot$ Marine pollution $\cdot$ Analytical chemistry $\cdot$ Wastewater

\section{Introduction}

The concentration of microplastics (MPs) in water ecosystems increases as plastic production gradually increases every fiscal year. Currently, almost $71 \%$ of plastic waste is directly absorbed by the environment, and the remaining waste is reused in a different format, resulting in higher microplastic pollution. In 2016, approximately 335 million metric tons of plastic products were manufactured, whereas, in 2017, this amount increased up to 348 million metric tons. Thus, global plastic production increased by approximately $4 \%$ within only

Responsible Editor: Philippe Garrigues

Mamun Jamal

mamun.jamal@chem.kuet.ac.bd

1 Department of Leather Engineering, Faculty of Mechanical Engineering, Khulna University of Engineering \& Technology, Khulna 9203, Bangladesh

2 Department of Chemistry, Faculty of Civil Engineering, Khulna University of Engineering \& Technology, Khulna 9203, Bangladesh
1 year (Europe 2017). At present, almost 8 million metric tons of plastic waste are directly mixing with the marine ecosystem each year, and this amount is projected to rise fourfold by 2050 (Derraik 2002). In 2004, 20- $\mu \mathrm{m}$ plastic particles were classified as MPs by marine biologist Richard Thompson (Thompson et al. 2004). However, in 2009, NOAA (National Oceanic and Atmospheric Administration) defined plastic particles with sizes of less than $5 \mathrm{~mm}$ as MPs, but the official definition and lower size limit of these particles have not yet been established (Arthur et al. 2009). These plastic particles are produced by the deterioration and peeling of various plastic wastes, resulting in environmental pollution (Hirai et al. 2011; Van Cauwenberghe et al. 2013; Law et al. 2014; Faure et al. 2015; Zhang et al. 2018). The level of toxicity of MPs depends on the chemical structures and the incorporation of other additives that ensure better cross-linking during the polymerization process (Meeker et al. 2009).

Researchers showed that a higher accumulation of MPs in aquatic environments led to the frequent exposure of living organisms to these plastic waste particles and unbalanced ecosystems (Sun et al. 2019). Studies also claimed that MPs could carry 
germs and travel more than $100 \mathrm{~km}$ via wind currents. Even in the current pandemic situation, people are infected by the viruslike novel coronavirus (SARS-CoV-2) without initiation by any affected patients in various places (Enyoh et al. 2020; Kampf et al. 2020). Therefore, further investigations of the impact of MPs, which might facilitate pandemic transmission due to their higher adsorption areas and the longer retention (up to 5 days) of micro-organisms on their surfaces, are needed. Recently, Santos et al. reviewed different analytical approaches for detecting MPs and highlighted the future need to do further study on the evolution of their detection and removal techniques, enabling the development of appropriate methodologies for minimizing microplastic pollution (Rocha-Santos and Duarte 2015).

Additionally, microplastic removal from wastewater has recently been reviewed by Poerio et al. (2019) and Padervand et al. (2020). Peorio et al. focused on microplastic removal by conventional filtration systems, and Padervand et al. provided a detailed explanation of coagulation techniques. However, limited information about microbial degradation and membrane filtration systems was subsumed in their studies. Sun et al. (2019) reviewed the occurrence, detection, and removal of MPs in wastewater treatment plants. The authors conducted an in-depth analysis of MPs, characterizing them by Fourier transform infrared spectroscopy (FTIR), Raman spectroscopy, and stereomicroscopy. Recently, a growing interest in MPs research within the research community has led to the use of more sophisticated methodologies for detection and removal purposes. Particular attention has been given to remote sensing techniques (i.e., satellite), thermal analysis, polarized light optical microscopy (PLM), atomic force microscopy (AFM), and a combination of different detection methods like AFM-IR, AFM-Raman spectroscopy, Raman spectroscopy with particle auto-detection, and image analyzer. Research on removal technologies for MPs is still in the preliminary stage, and 35$59 \%, 50-98 \%, 0.2-14 \%$, and $0.2-2 \%$ microplastic removal have been achieved by preliminary, primary, secondary, and tertiary treatments, respectively, in wastewater treatment plants. However, in most cases, limited information was given about microbial degradation in biological treatment systems, which can potentially be used in secondary treatment processes. In addition, a number of new and noteworthy technologies for microplastic removal from wastewater have also been introduced.

As a result, the main focus of this review is an in-depth presentation of the gradual introduction and utilization of different detection and removal methods for MPs in wastewater to ensure correct experimentation. To this point, the incorporated information provides a clear concept in a single report to enable a quick understanding of the current status of the microplastic detection field. It summarizes the severe environmental impact of microplastic pollution, which is essential to focus on before determining more effective clean-up methods.
A thorough review is then provided of conventionalized removal methods, which have already been developed, for example, membrane filtration, adsorption, biofiltration, magnetic extraction, and microbial degradation. The significant parameters of these techniques, including the contact time, incubation time, $\mathrm{pH}$, temperature, stirring rate, removal efficiency, advantages, and disadvantages, are also described. In this study, it is found that bacteria can degrade MPs in wastewater through the formation of enzyme-like PETase and MHETase. Thus, it is worth investigating more micro-organisms that can form these types of enzymes to degrade and minimize microplastic pollution. At a glance, this study provides a clear and straightforward understanding of MPs and successfully analyzes all the associated issues.

\section{Microplastic detection}

\section{Attributes of microplastics}

Microplastics (MPs) are ubiquitous as a solid form in the environment with various dimensions, structures, densities, colors, types of polymers, and incorporation of plastic particles with other pollutants (Fig. 1). Transportation phenomena of MPs in the ecosystem are solely related to these characteristics (Lambert et al. 2017). Small plastic particles (PPs) are mostly available in different water bodies. For example, in China, the presence of small PPs was identified in different estuaries (Zhao et al. 2014, 2015), Lake Taihu of Yangtze delta (Su et al. 2016), Wuhan urban water systems (Wang et al. 2017b). On the other hand, larger PPs were more available in the Siling Co basin and the Bay of Jiangxi (Zhang et al. 2016). However, weathering process makes the large plastics to small PPs (Lambert and Wagner 2016). At this moment, there is lack of available data on the distribution of PP sizes in environment which raises concern to the research community, and need to find appropriate methods for this purpose (Zhang et al. 2018).

Based on morphological analysis, MPs can be in six categories, fiber, sphere, foam, sheet, fragment, and film (Table 1). Fiber-shaped MPs are mostly found in the environment (Zhang et al. 2018). The average concentrations and size range of microfibers in water are 0.02-25.8 fibers/L and 0.09$27.06 \mathrm{~mm}$, respectively (Suaria et al. 2020). Garment industries are the primary source of discharging microfibers, and it mainly comes from the washings at different stages in manufacturing (Cesa et al. 2017). Countries with substantial garment industries such as Bangladesh, China, Vietnam, and India may be responsible for the discharge of a considerable amount of microfibers into the environment. Foam-type plastic particles are formed through the fragmentation of different plastic-based products, while plastic synthetic bags and packing ingredients are responsible for film-structured MPs 
(a)

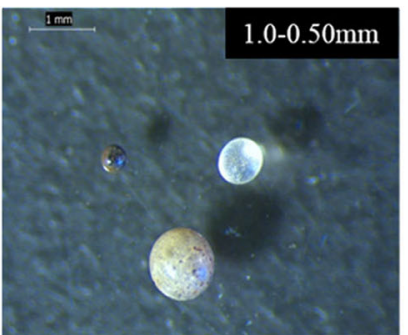

(b)

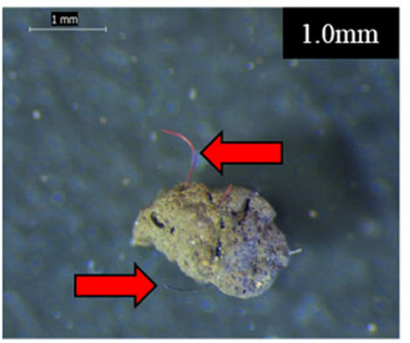

(c)

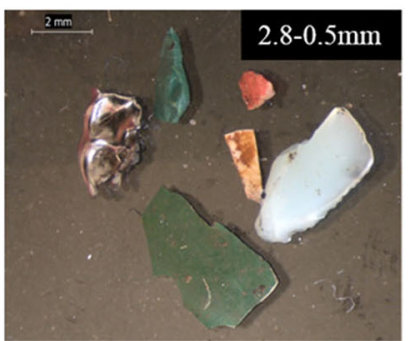

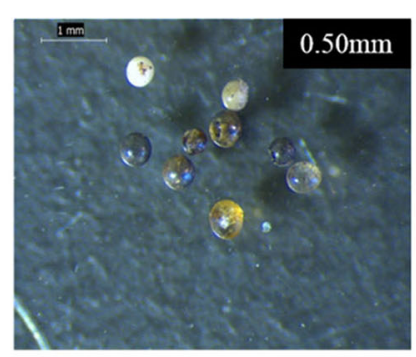
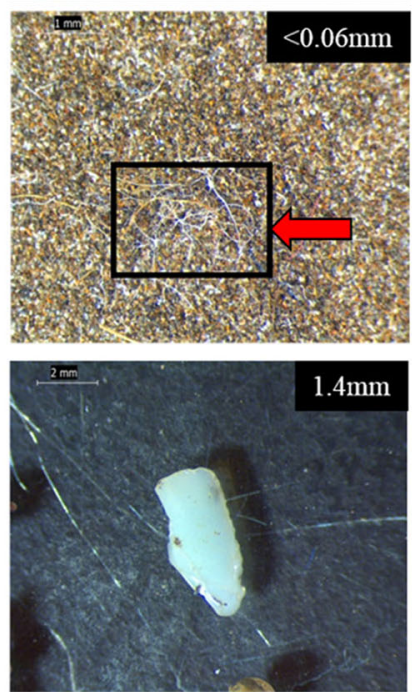
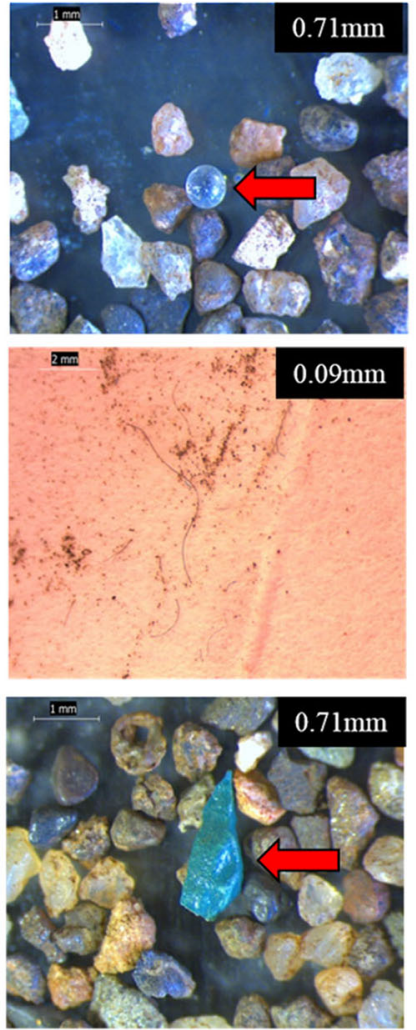
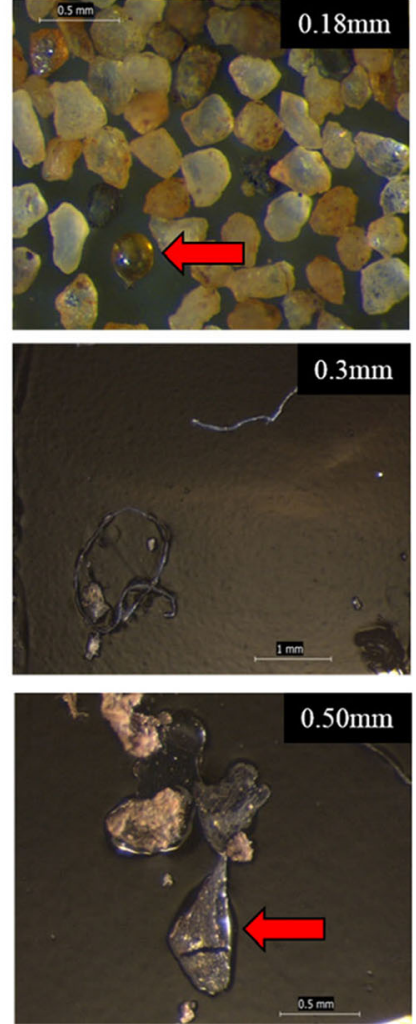

Fig. 1 Light microscopy images of suspected microplastics in size-fractionated sediment samples from the River Kelvin in suspended and settled material before chemical characterization. Items shown are pellets (a), fibers (b), and fragments (c) (Blair et al. 2019)

(Zhang et al. 2015). Sphere-type particles originate from resin pellet leakage of the transportation system, abrasive blasting media, and different abrasive products (Acosta-Coley and Olivero-Verbel 2015).

Both transparent and colored MPs are available in the environment. For example, in China, colorless particles were available in the sample of Yangtze Estuary, Ch'inghai Lake. On the other hand, colored plastic debris was present in the specimen from Lake Tai and Estuary in urban areas (Zhao et al. 2014, 2015; Su et al. 2016; Peng et al. 2017; Di and Wang 2018). Colored PPs usually originate from long life cycle plastic packaging, and transparent particles come from disposable and short life cycle plastics such as pots, bottles, and bags (Zhang et al. 2018).

Thus, it should be noted that the majority of fiber-shaped microplastics are available in the environments from the rapid discharge of the clothing industry, while all of these particles are also increasingly fragmented through the process of weathering. Further research is also needed to confirm the standard size distribution to categorize the available MPs.

From the statistics (Table 1), we can see that most MPs are colorless in sizes ranging from 0.1 to $5.0 \mathrm{~mm}$. Also, PE- and PS-based MPs are frequently observed in the different analyses shown in Table 1. It may attribute to the frequent exposure of waste plastic utensils and the washings of garments into the environment.

\section{Methods of detection}

Due to variation in size, structure, color, and type of polymer, it is challenging to detect MPs using a single detection method. Multi-detection techniques are therefore used for this purpose. Usually, microplastic detection can be categorized into two steps, one being physical (i.e., color, size), and the other being chemical (i.e., composition, structure) identification (Shim et al. 2017; Sun et al. 2019). Visual analysis, i.e., unaided eyes with forceps, is used to identify larger and some small colored MPs (Heo et al. 2013). There is a high chance, however, that most small particles will be missed during analysis. It is, therefore, an easy and fast preliminary identifying step (Hidalgo-Ruz and Thiel 2013). Thus, further progress is inevitable to provide a profound detail of the MPs, which triggers the evolution in MPs detection.

The stereomicroscope is mainly used for morphological analysis and counting of MPs. However, due to its lower magnification capacity, it has a size limitation, and its detection efficiency depends on its user. It is estimated that up to $70 \%$ of the measurement error can occur during the test, and this percentage of error will increase as the particle size decreases (Hidalgo-Ruz et al. 2012). This technique is complicated to distinguish between cotton-based synthetic fibers and naturally available fibers (Jamal et al. 2004). It is also difficult to discern different colored samples (Murphy et al. 2016). 
There is also a substantial risk that samples of significant numbers will be skipped or duplicated. Several steps are carried out to eliminate this error, such as using Petri dishes with a grid to count MPs (Carr et al. 2016). Researchers use a burner to separate synthetic and natural fibers because synthetic plastic fibers can be easily liquefied with heat, which is not the case for natural fibers. To increase accuracy, the sample can be stained before visualization through a microscope. For example, a pink stain (Rose Bengal staining solution) can be used to differentiate natural fiber over synthetic one (Ziajahromi et al. 2017). Such sample pretreatment may be performed to eliminate the error of stereomicroscopic detection. This method also has some inherent drawbacks, including more time-consuming and labor-intensive, and being unable to differentiate between different polymers (Sun et al. 2019). However, it will be the best act to assign this technique to detect comparatively larger sized particles $(>5 \mathrm{~mm}$ ) with prescribed pretreatment to minimize the test error.

Scanning electron microscopy (SEM) is installed for the physical analysis of MPs to overcome the limitation possesses by a stereomicroscope. SEM provides highdefinition clear images of the external surface of MPs, making it easy to distinguish between synthetic MPs and various organic materials that can be found with MPs (Cooper and Corcoran 2010). Also, energy-dispersive X-ray spectroscopy (EDS) is used for elementary analysis to determine the chemical compositions of plastic particles. However, it would be difficult to have access to SEM-EDX regularly, as it is an expensive method of detection and requires more time and effort to prepare the sample, thus not handling a large number of samples. Furthermore, SEM-EDX cannot distinguish colored MPs. However, this central laboratory method can be used as a confirmatory technique for detecting MPs (Shim et al. 2017). Here it is worth mentioning that this method's error might be reduced through the utilization of fluorescent dyes (fluorescein isophosphate, Nile red, and Safranin T) at high temperatures. Due to the loosening of the plastic macromolecular chain, the penetration of dye molecules is simple at a higher temperature. At ambient, the structure and the encapsulation of dye molecules can be tightened into plastic particles simultaneously.

Advance and updated microscopic analysis such as PLM (polarized light microscopy) can also be used for the analysis of PET-, PP-, and PE-based MPs. The crystallinity of plastics can be differentiated based on source polymers and manufacturing processes. As a result, polarized light passes through the plastics, while the crystallinity of plastic influences this passing light and is used to detect microplastic. However, PLM cannot detect opaque and thick MPs (Sierra et al. 2020). Thus, a further review could be carried out to confirm the standard distribution of the size and color of MPs to minimize the process error of PLM. 
To improve the detection accuracy, the chemical analysis of MPs plays a vital role, and, at the same time, the chemical composition can be measured with this analysis. There are two methods of chemical characteristics as destructive and nondestructive methods. Non-destructive methods are Raman spectroscopy and FTIR, while destructive methods are liquid chromatography (LC), gas chromatography connected with mass spectrometry (GC-MS), subsuming pyrolysis gas chromatography-mass spectrometry, and thermal desorption gas chromatography (Browne et al. 2011; Fries et al. 2013; Dekiff et al. 2014; Nuelle et al. 2014; Hintersteiner et al. 2015; Löder et al. 2015; Dümichen et al. 2017; Elert et al. 2017; Erni-Cassola et al. 2017; Mintenig et al. 2017; Araujo et al. 2018; Lares et al. 2018). Among them, spectroscopic techniques are widely accepted analytical techniques for this purpose (Hidalgo-Ruz et al. 2012).

FTIR is a mostly used non-destructive technique for the detection of MPs. In this method, plastic particles are exposed to infrared radiation, and an appropriate spectrum is formed for the vibration of a chemical bond between different atoms. The obtained spectrum is then compared to the reference spectrum stored in the library to analyze the compositions of plastic particles (Murphy et al. 2016). It is therefore essential to develop a library with a non-typical spectrum of plastics as a reference from different plastic sources to ensure the relevant comparison of plastic particles. Although it has a wide range of facilities for detecting microplastic, this process is laborintensive, as the sample needs to be adjusted under an optical microscope, and spectrum analysis can then be performed for individual microplastic (Harrison et al. 2012). However, the adjustment of the sample is still a challenge in these methods. Incorporating auto particle detection with an image analyzer would minimize process strain and improve data accuracy.

Recently developed focal plane array-Fourier transform infrared spectroscopy (FPA-FTIR) can provide a large spectrum of each particle and result in higher detection efficiency (Löder et al. 2015). For example, the researcher has shown that FPA-FTIR could provide a better explanation for a plastic-based sample of both the water treatment plant and the sludge. It has been claimed that high-definition images of samples could be obtained by infrared transmission rather than by infrared reflection (Mintenig et al. 2017). However, drawbacks are still aligned with this method as too difficult to identify stretched fiber images, limited diffraction span of $10 \mu \mathrm{m}$ per $1000 \mathrm{~cm}$, and particles of less than 10 to $20 \mu \mathrm{m}$ are difficult to analyze (Li et al. 2018b). Also, Yu et al. (2019) introduced TGA-coupled FTIR to distinguish PVC and PS in mussels and seawater. It detects MPs by polymer pyrolysis, followed by FTIR analysis. But this is a destructive method and cannot be used to investigate the attributes of plastic particles.

Raman spectroscopy is another technique widely used for the identification of MPs. It is a technique of vibrational spectroscopy that works based on inelastic light scattering. It provides finer spatial resolution (number of pixels used to form a digital image) over FTIR on this concern (Schymanski et al. 2018). It also has a high reactivity to the non-polar group and cannot be affected by the matrix effect from the environment, such as $\mathrm{CO}_{2}$ and water ( $\mathrm{Li}$ et al. 2018b). However, Raman spectrum can be affected by fluorescence; thereby, sample pretreatment is needed before doing Raman analysis (Elert et al. 2017). Besides, lipophilically stained plastic particles (Nile red) can improve the analysis's accuracy (Erni-Cassola et al. 2017).

The thermoanalytical analysis is also be used to identify the chemical characteristics of MPs as an alternative to spectroscopy. It is a destructive method, though, and the principle of this method is to measure the difference in the physical and chemical properties of different polymers based on thermal stability (Majewsky et al. 2016; Dümichen et al. 2015). For example, differential scanning calorimetry (DSC) is mostly used to determine different polymer materials (Tsukame et al. 1997). Reference materials must be used to determine the type of polymer due to the variety of plastic characteristics. This can identify primary MPs such as PE-based microbeads. Thermal gravimetric analysis with a DSC combination can detect both PP and PE (Majewsky et al. 2016). Plastic polymers can also be detected using pyrolysis gas chromatography-mass spectrometry (Pyro-GC-MS). In this method, MPs are heated to be decomposed and then separated and detected by GC-MS. Here, the generated pyrogram of each sample is compared to the standard pyrogram as a reference. For example, small plastic particles $(0.35$ to $7.0 \mathrm{mg})$ are pyrolysed at $700{ }^{\circ} \mathrm{C}$ and then analyzed by GC-MS. This method can detect MPs (i.e., PE, PP, PVC, PS, PA, PET) in sediments (Fabbri et al. 2000, Fabbri 2001, Fries et al. 2013, Dekiff et al. 2014, Nuelle, Dekiff et al. 2014). Although GCMS is a reliable central laboratory-based method to analyze MPs, this is destructive and time-consuming. It is also laborintensive as each pyrogram of individual sample required to be compared with standard program. So, the investigation on auto image analyzer incorporation with this process may be carried out to enhance the process accuracy.

The newly introduced remote sensing method can detect floating MPs of the coastal water surface using a satellite subpixel scale image. In this analysis, the Naive Bayes (Bayesian) algorithm is used to synchronize MPs sensing data and ensures $86 \%$ accuracy of detection (Biermann et al. 2020). The combination of Raman spectroscopy, auto particle detection, and image analysis is also used for the identification of MPs in different samples. In this process, plastic particles are placed on a single-layer glass and automatically counted one by one, while both an image analyzer and spectroscopy are performed simultaneously. By following this method, the attributes of MPs can be easily defined (Shim et al. 2017). At present, the majority of AFM and IR or Raman spectroscopy 
combinations are used for nanoplastic analysis. AFM can provide nanometer resolution images of particles. AFM-IR is the combined use of two tools. During analysis, the sample tends to change its structure, size, volume with temperature changes due to the absorption of IR and increase the oscillations of the cantilever. The pattern is then analyzed by Fourier transform to determine the amplitudes as well as the frequencies of the cantilever oscillations, resulting in a resolution of 50-100 nm (Dazzi et al. 2015). If the sample is unknown, it is difficult and time-consuming to focus on nano-sized particles by using AFM-IR (Shim et al. 2017). Table 2 presents the advantages and disadvantages of the methods of detection of MPs.

Here it is worth mentioning that the evolution of microplastic detection happened on the basis of process optimization, specifically, the magnification of particles, surface analysis, image construction, data analyzer, sample preparation, and dwell time. Still, there is a vacuum to characterize MPs within a wide range of polymers, rapid detection, and ultimate data analysis. So, the integration of IR spectroscopy with auto-detection and image analyzer facility can enhance the process optimization.

\section{Origin of microplastics}

The presence of plastic particles in the environment is identified by analyzing the aquatic ecosystem (Fig. 2). The analysis includes observation of the plankton sample, experimenting with sediments, observation of both invertebrates and vertebrates, and analysis of interactions between pollutants and chemicals. The analysis confirmed that MPs are littered in the environment from different sources (do Sul and Costa 2014). These plastic particles are now ubiquitous in marine and freshwater ecosystem with different particle sizes based on transport media such as marine waves and wind. The nature of the polymer available is thermoplastics. So they can be easily and repeatedly recycled by heating, cooling, and molding. Also, some plastic materials are thermosets. They are irreversible and cannot be remolded, reheated, reused after a single process of heating and molding, and directly discharged into the environment (Galgani et al. 2013; Talvitie et al. $2017 \mathrm{a}, \mathrm{b}$ ). The primary source of plastic particles is the emission of plastic waste particles from the clothing industry, the cosmetics industry, the plastic manufacturing plant, the fishing industry, the shipping line, the sewage treatment plant, the car and truck tires, and the air blasting (Scheme 1).

Discharge of MPs from secondary sources, including degradation of large plastics to smaller ones under different environmental conditions, such as mechanical fragmentation and ultraviolet light (Eriksen et al. 2014). The clothing industry is a source of plastic particles, where polystyrene is a cheap alternative to cotton and emits around 100 fibers per liter of wastewater during the wash operation (Browne et al. 2011). Besides, a different type of artificial fibers such as nylon,

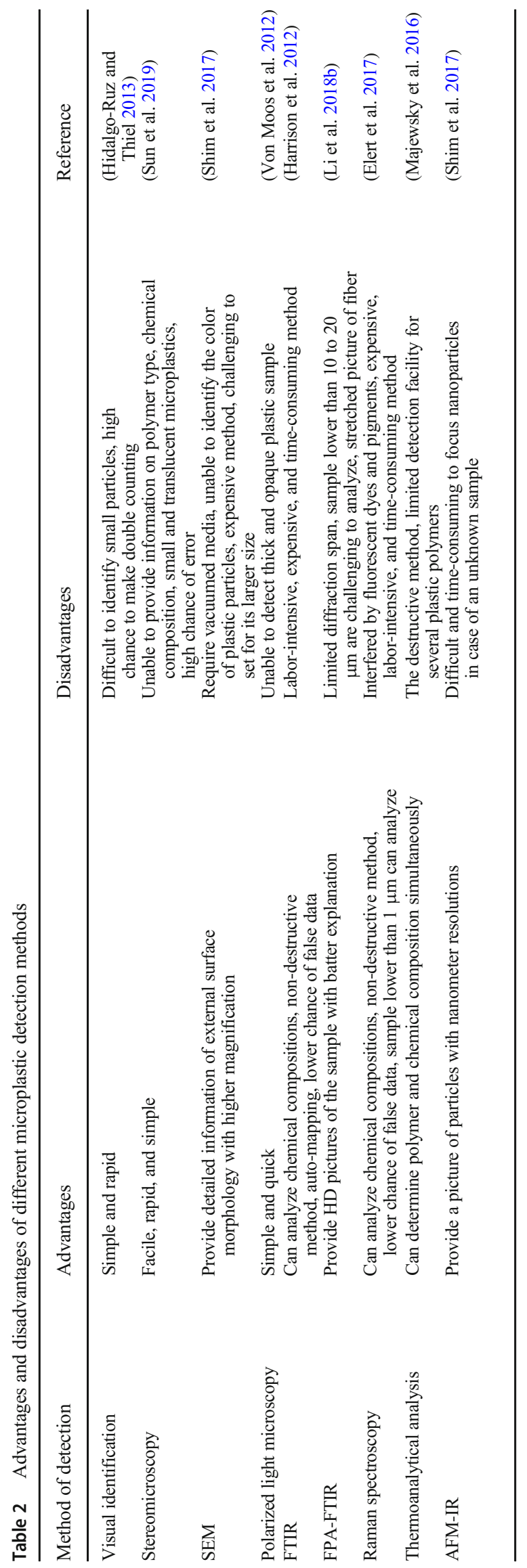


Fig. 2 Evolution and impact of microplastic detection

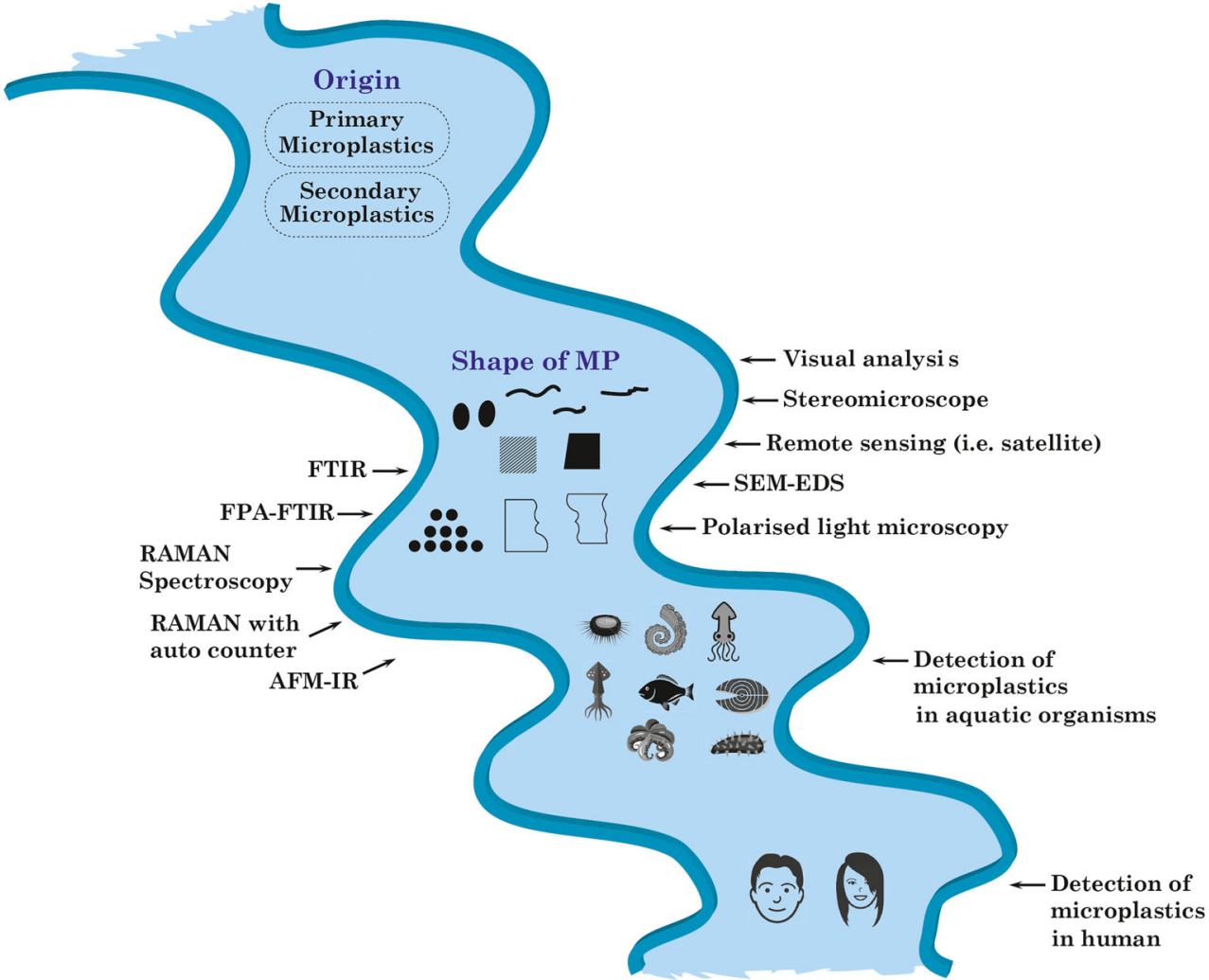

spandex, acrylics, and polyester are used in the textile industries. In general, more than 700,000 synthetic fibers can be released into the environment by washing $6 \mathrm{~kg}$ of clothing loads (Napper and Thompson 2016). Cosmetic industries are also responsible for reducing MPs due to the replacement of natural exfoliating materials with synthetic micro-exfoliates. A wide variety of MPs such as nylon, PET, and PP are frequently used in personal care products. As a result, these plastic particles are discharged directly into the sewage treatment systems after use (Zitko and Hanlon 1991). The conventional water treatment plant can remove approximately $95.0-99.9 \%$ of MPs. However, 0-7 MPs per liter is emitted into the environment even after treatment. In sum, it is assumed that every day, the water treatment plant discharges 160 trillion liters of effluents with 8 trillion plastic particles into the aquatic ecosystem, while 808 trillion microbeads are released from household activities within a single day due to extensive use of cosmetics for personal use (Anderson et al. 2016). Plastic manufacturing plant releases plastic debris due to the use of resin pellets and granules as raw ingredients. Most of the industrial sites are located near water bodies. As a result, plant effluents are directly discharged into the water ecosystem. In Sweden, for example, the average concentration of plastic particles is between 150 and $2400 / \mathrm{m}^{3}$. But the plastic concentration is higher near the production plant and is around 102,000 MPs per $\mathrm{m}^{3}$. It can therefore easily be assumed that a large volume of plastic waste is being disposed of in the environmental ecosystem without any treatment (Cole et al. 2011). Also, accidental leakage during shipment, mishandling of packaging materials, may cause pollution of water bodies.
Scheme 1 Origin of microplastics

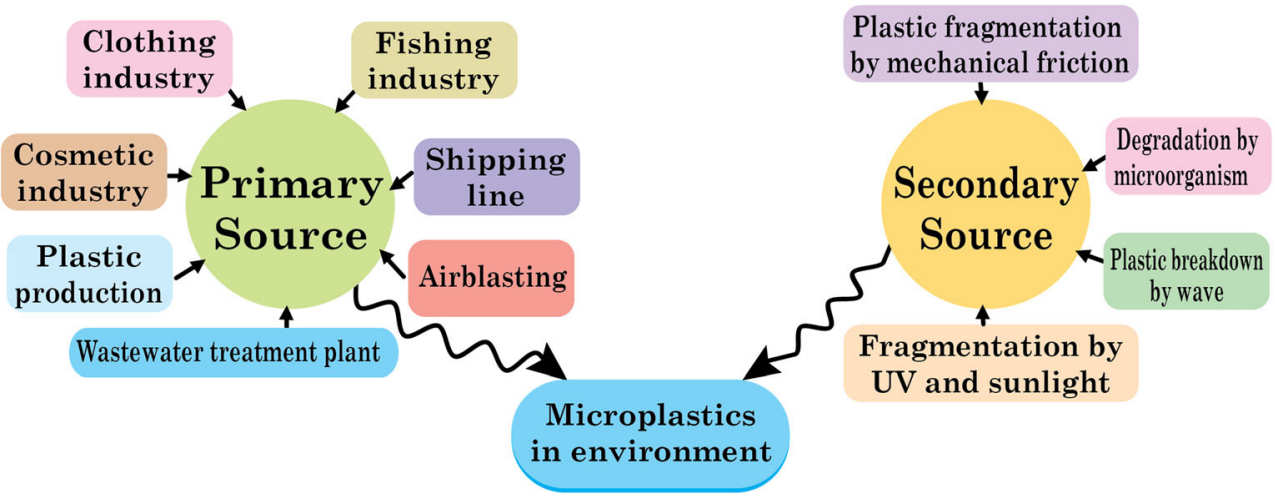


Recreational and commercial vessels, fish-processing industries, drain plastics into the marine ecosystem and, in the long run, are fragmented to the secondary MPs. Fishing methods, including nylon fishing nets and monofilament fishing lines, are frequently discarded and accumulated in a variety of seafood. For example, 55\% of fish species in Indonesia contain MPs, whereas $67 \%$ of fish species in the USA contain MPs (Rochman et al. 2015). Wastewater treatment plants also consider the primary source of plastic particles (Browne et al. 2011; Long et al. 2019). During wastewater treatment, larger sized plastic particles can be removed effectively, while MPs can be easily ignored in different treatment units. For this purpose, MPs are quickly discharged and accumulated in water bodies (Murphy et al. 2016). Many water treatment plants are adjacent to marine or fresh water bodies, resulting in the continuous discharge of plastic particles. For example, approximately 3340 water treatment are fully operational in China with a daily wastewater treatment capacity of $78 \times$ $10^{6} \mathrm{~m}^{3}$. Of these, $1873(56 \%)$ treatment plants are located near the coastal zone and directly as well as indirectly drained effluents into water ecosystem (Jin et al. 2014). As a result, research is being conducted to investigate origin, transportation, impact, detection, and efficacy of microplastic separation in effluent treatment plants. However, further degradation and transportation of the MPs are happening due to the direct dumping of plastic wastes into the environment. So, source segregation may be helpful for on-site MPs control rather than central treatment system. Specifically, compatible separation method is necessary in each commercial production plant as well as household to cut off the emission of MPs so that there will be no probability for fragmentation and accumulation of microplastics into the environment at a larger scale.

\section{Transportation phenomena of microplastics}

There are several pathways for the transportation of plastic particles, such as domestic wastewater discharge, emission from sewage treatment plants, stormwater drainage, and wind blowing (Scheme 2) (Mason et al. 2016; Nizzetto et al. 2016; Dris et al. 2017; Siegfried et al. 2017). The wastewater discharge from different domestic activities is the prime sources and pathways of MPs, such as different artificial fibers and micro-exfoliates to the environment. In rural areas, wastewater is discharged into the environment with or without treatment, while in urban areas, wastewater from domestic sources is treated in a wastewater treatment plant. These treatment plants can remove a significant amount of MPs, but a good volume of MPs is still released into the aquatic ecosystem by overtaking different treatment phases in plants (Murphy et al. 2016). Settled sludge contained a considerable portion of plastic particles in the water refining plant, and the application of this sludge for landfilling can expose MPs to the soil ecosystem (Mahon et al. 2017). The drainage of stormwater is another pathway for the migration of macro- and microplastic particles into the aquatic ecosystem. Due to the lack of accurate waste management, plastic wastes are ubiquitous and accumulated through rainwater runoff in the terrestrial system, such as cultivable soil, roads, landfills (Zhang et al. 2018). MPs from tires and road wear particles can be migrated to the environment by road drainage, and this source is responsible for the drainage of $42 \%$ of plastic particles migrating from the river to the marine ecosystem (Nizzetto et al. 2016; Siegfried et al. 2017).

Since both macro and MPs are not heavy, the atmospheric wind can transport these particles to the water bodies. They can travel too far by wind blow from their actual origin. The transportation behavior of MPs is not yet well understood. But oceans are considered primary sinks for plastic particles, while terrestrial and freshwater ecosystems are considered primary source of MPs. During migration, MPs can be further fragmented and deposited in sediments of water bodies and the shoreline. The submerging tendency of MPs is related to the structure, dimension, and density that can be changed by weathering and biological fouling. Simultaneously, the water flow rate is also responsible for the precipitation of plastics in sediments (Kowalski et al. 2016; Horton et al. 2017). It is noted that biological fouling is related to sunlight, nutrient levels, water temperature, and hydraulics. MPs can go through mechanical and chemical breakdown several times after entering the water environment. Fragmentation may occur during flotation due to photo-oxidation of plastic particles by ultraviolet and visible sunlight. However, the presence of turbid water and biological fouling may cause an interruption in this process. Mechanical pressure also contributes to the fragmentation of fragile and degraded MPs.

Further degradation may occur by micro-organisms, depending on the type of polymers, type of organisms, plastic molecular weight, and environmental conditions. This deterioration process is also furthered by ionization, hydrolysis, and plastic particles' solubilization (Gu 2003). Fragmentation of plastic waste is a slow process but can be catalyzed by withering due to a change in surface texture. This change can also assist micro-organisms in the attachment of MPs as well as rapid degradation (Welden and Cowie 2017). Research has shown that MPs can be consumed by aquatic creatures with a potential threat. So, it is lucid to claim that surface water wave is mostly responsible for the transportation of MPs while sunlight causes the rapid degradation of plastic particles. Thus, the complete separation of MPs in wastewater treatment plant should be ensured. Simultaneously, sludge management is also important to conduct more cautiously before dumping into the landfilling site to stop the leaching of plastic particles into the water media.

Also, the digestion of MPs by sea creatures causes these floating plastic particles to sink (Cole et al. 2013, 2016; Jabeen et al. 2017; Katija et al. 2017; Silva-Cavalcanti et al. 2017). 


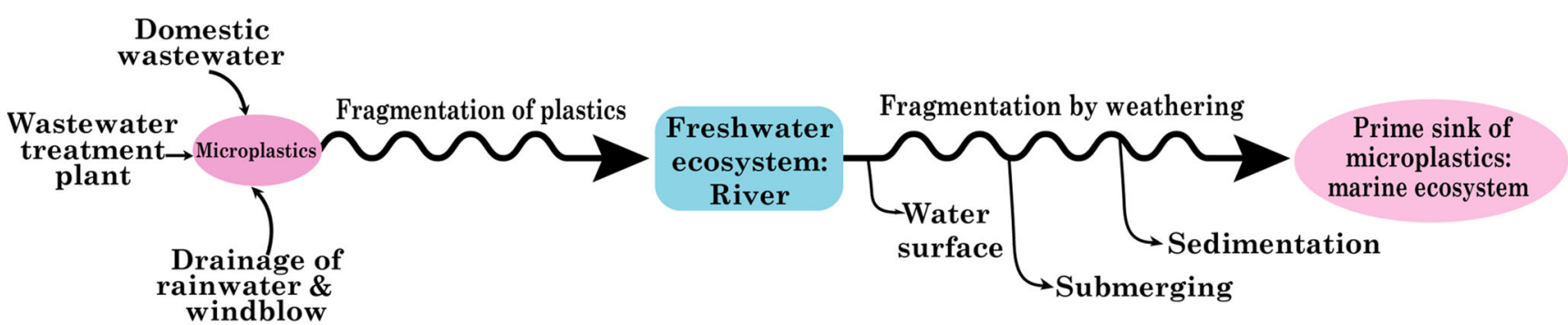

Scheme 2 Fate and pathways of microplastics

Various studies have shown that bioaccumulation, bio-amplification, and MPs migration could occur after entering the water environment. Thus, it can be confirmed that aquatic creatures can digest a significant amount of plastic particles, and further degradation has occurred in their digestive system due to the presence of peristalsis, various internal micro-organisms, and intestinal secretion (Yang et al. 2015b; Su et al. 2016).

\section{Impact of microplastics}

\section{On human health}

For humans, fish is considered to be a promising source of protein. Thus, at the end of the food chain, people consumed a wide variety of fish and crustaceans and, at the same time, ingested microplastics (MPs) through this species. As a result, this type of consumption poses a potential threat to human health and has become an emerging concern in recent years (Wright and Kelly 2017; De-la-Torre 2019). MPs are available in the organs (intestine, tissue) of various aquatic animals such as fish, crustaceans, and bivalves (Li et al. 2015; Bessa et al. 2018; Naji et al. 2018). Various factors, such as shape, color, size, and density, are responsible for this bioavailability of MPs to aquatic species (Wright et al. 2013). The study showed that MPs could be accumulated on the tissues of the mussels and the latex-based spheres observed on the gill's surface in different portions of rainbow trout fish epidermal cell surface under the skin phagocytes. It is, therefore, clear that epithelial cells make a significant contribution to the adherence and penetration of plastic particles into the fish body. As a result, direct consumption of these gills and skin surfaces could be a possible way for MPs to be exposed to human food habits ( $\mathrm{Su}$ et al. 2018; Kolandhasamy et al. 2018). Like seafood, MPs is also available in sea salt, and this presence has been confirmed by various research studies. Approximately 17 salt samples from 8 different countries were analyzed, and an average of $0-10$ plastic particles per $\mathrm{kg}$ was identified (Yang et al. 2015a; Iñiguez et al. 2017). On the other hand, the investigation also confirmed the presence of MPs in Spanish and Chinese table salts (Yang et al. 2015a, Iñiguez et al. 2017). Moreover, fragmented and line-shaped MPs is also available in both honey and sugar. However, there are also disputes regarding the presence of MPs in honey because one study found that MPs migrated to honey via atmospheric wind, while another study found no significant amount in honey (Liebezeit and Liebezeit 2013; Mühlschlegel et al. 2017). A significant concentration of plastic particles in tap water and bottled water was detected (Schymanski et al. 2018). Microplastics is also present in canned foods such as sprat and sardine. Twenty brands of canned food were analyzed, and at least 1-3 MPs were detected in 4 brands. The presence of MPs with a high concentration in canned food has therefore become an emerging concern in recent years. According to experts, rules and restrictions should be imposed on eradicating these health hazards (Karami et al. 2018).

Table 3 shows the concentration of MPs present in different edible foods. Therefore, the most commonly found polymers in food products are PET, PVC, PE, PP, PES, PA, and PS. These MPs pose a potential threat to human health as they can adsorb various toxic chemicals from the environment. According to the GHS (Globally Harmonized System of Classification and Labelling of Chemicals), more than $50 \%$ of plastic products contain toxic chemicals, hazardous additive polymers, and monomers (Lithner et al. 2011). Among the different plastic polymers, PET is mainly used for plastic products such as drinking water bottles, building insulation materials, pipes, and food packaging materials. However, frequent exposure to this plastic polymer could pose a potential threat to human health due to its carcinogenic effect ( $\mathrm{Li}$ et al. 2016). Another plastic polymer called PS is also famous for use in different plastic utensils.

Some plastics, such as PVC and PS, are responsible for discharging hazardous monomers that can cause cancer in humans (Wang et al. 2016). In addition, different PVC additives may accumulate in human blood. On the contrary, PS-based nanoplastics can damage the morphology of the gastric adenocarcinoma cell, cell viability, and inflammation to activate gene expression in humans (Mettang et al. 1996). Inhalation of plastic particles is also hazardous, as these MPs can act as a potential vector for various pollutants, toxic pathogens, and chemical parasites in humans (Vethaak and Leslie 2016). Human lungs and gastrointestinal tract (GIT) can also be damaged by the uptake of MPs, where endocytosis is a key mechanism for this. 
Table 3 Microplastics in different edible food items

\begin{tabular}{|c|c|c|c|}
\hline Name of different edible foods & Amount of microplastics & Types of polymer & References \\
\hline Commercial and non-commercial fishes & $0-3$ particles/fish & PVC, PE, PS, and PP & (Baalkhuyur et al. 2018) \\
\hline Bottled drinking water & $50 \pm 2$ microplastics/liter & PE, PET, and PP & (Schymanski et al. 2018) \\
\hline Canned sprats and sardines & 1-3 particles/fish & PE, PP, PVC, and PET & (Karami et al. 2018) \\
\hline Table salt & 550-681 microplastics $/ \mathrm{kg}$ & PET, cellophane, and PE & (Yang et al. 2015a) \\
\hline Sea salt & 50-280 microplastics $/ \mathrm{kg}$ & PET, PVC, PA, PP, PMMA & (Iñiguez et al. 2017) \\
\hline Honey & $\begin{array}{l}\text { Black plastic particles } 1760-8680 / \mathrm{kg}, \\
\text { transparent fibers } 132-728 / \mathrm{kg}, \\
\text { transparent microplastics } 60-172 / \mathrm{kg} \text {, } \\
\text { colored fibers } 32-108 / \mathrm{kg}\end{array}$ & Cellulose or PET & (Mühlschlegel et al. 2017) \\
\hline Dried fish & 61 microplastics/fish & PET, PP, PS, and PE & (Karami et al. 2017) \\
\hline Marine mussels & $3.0 \pm 0.9$ microplastics $/ \mathrm{g}$ & Polyester, PET, and PUR & (Catarino et al. 2018) \\
\hline Wild oysters & $\begin{array}{l}1.5-7.2 \text { microplastics/g of } \\
\text { tissue in wet condition }\end{array}$ & PVC, PET, and PA & (Li et al. 2018a) \\
\hline $\begin{array}{l}\text { European pilchard and } \\
\text { European anchovy }\end{array}$ & $0-3$ microplastics/fish & PA, polyacrylamide, and PET, & (Compa et al. 2018) \\
\hline Atlantic cod & $18.8 \%$ of plastic polymers & Polyester, PVC, PES, PE, and PP & (Bråte et al. 2016) \\
\hline $\begin{array}{l}\text { Yellowfin bream, sea mullet, } \\
\text { and silver biddy }\end{array}$ & $0.2-4.6$ particles/fish & $\begin{array}{l}\text { Polyester, mixing of acrylic } \\
\text { with polyester, and rayon }\end{array}$ & (Halstead et al. 2018) \\
\hline Japanese anchovy & $\begin{array}{l}2.3 \text { fragments and max } 15 \\
\text { particles per fish }\end{array}$ & $\mathrm{PP}$ and $\mathrm{PE}$ & (Tanaka and Takada 2016) \\
\hline Marine pelagic fish and demersal fish & $1.90 \pm 0.10$ microplastics/fish & PA, PS, and PES & (Lusher et al. 2013) \\
\hline Marine pelagic fish and demersal fish & 54 plastics/mg of fish & $\begin{array}{l}\text { PET, PUR, PS, PA, PE, } \\
\text { PP, PET, and PES }\end{array}$ & (Rummel et al. 2016) \\
\hline Well salts & 7-204 microplastics $/ \mathrm{kg}$ & PET, PE, and cellophane & (Yang et al. 2015a) \\
\hline Lake salts & 43-364 microplastics $/ \mathrm{kg}$ & PET, PE and cellophane & (Yang et al. 2015a) \\
\hline
\end{tabular}

$P S$ polystyrene, $P V C$ polyvinylchloride, $P A$ polyamide, $P E T$ polyethylene terephthalate, $P C$ polycarbonate, $P P$ polypropylene, $P E S$ polyester, $P E$ polyethylene, $P U R$ polyurethane, $P M M A$ polymethyl methacrylate

Also, the ingestion of microplastics can be transferred to other organs through GIT circulatory systems, and some key factors play a vital role, such as the associated protein corona, particle size, hydrophobicity, surface functionalization, and surface loading. Small plastic particles, such as PS-based nanoplastics, are more likely to translocate through the GIT circulatory system and are widely available in the blood and other organs (Jani et al. 1990). MPs may also be responsible for lung cancer as the presence of different synthetic fibers in the lung tissue of these cancer patients has been identified (Pauly et al. 1998). The most widely used additives for plastic productions are bisphenol A (BPA), brominated flame retardants (BFR), phthalates, triclosan, nonylphenol, and organotin compounds. It is claimed that BPA and nonylphenol can leach to biological cells during the ingestion of microplasticcontaining organisms (Koelmans et al. 2014). This hazardous bisphenol $\mathrm{A}$ is used as an antioxidant or plasticizer in most plastics. Exposure to these plastic products as food containers can therefore contaminate foods with BPA leaching. It causes various health problems, including liver malfunction, lowering insulin resistance, altering the reproductive system, brain malfunction, and problems in the womb of pregnant women. BPA also acts as a thyroid hormone inhibitor, attenuating the performance of pancreatic beta cells, increasing cardiovascular problems and obesity (Moriyama et al. 2002; Lang et al. 2008; Ropero et al. 2008; Melzer et al. 2012; Guart et al. 2013; Cipelli et al. 2014; Rani et al. 2015; Srivastava and Godara 2017). Another additive, such as phthalates, is also used as a plasticizer in plastics and is responsible for health problems involving sexual abnormalities, birth problems, and carcinogens (Gómez and Gallart-Ayala 2018). Thus, MPs cause various diseases due to the carcinogenic effect of different additives of polymer-based MPs. Besides, the tendency of MPs to act as a vector of other pollutants like heavy metals and pathogenic micro-organisms is also prone to make difficulties at long-term exposure to human health. A variety of diseases, including malfunctioning of GIT, lung cancer, obesity, respiratory problems, birth defects, cardiovascular diseases, viral diseases, and asthma are also noticed because of MPs pollution (Scheme 3).

\section{On aquatic organisms}

The amplitude of MPs is also increasing at the same time as the human population increases. Although differently shaped MPs such as line, fragments, foam, sheet, and globule is 


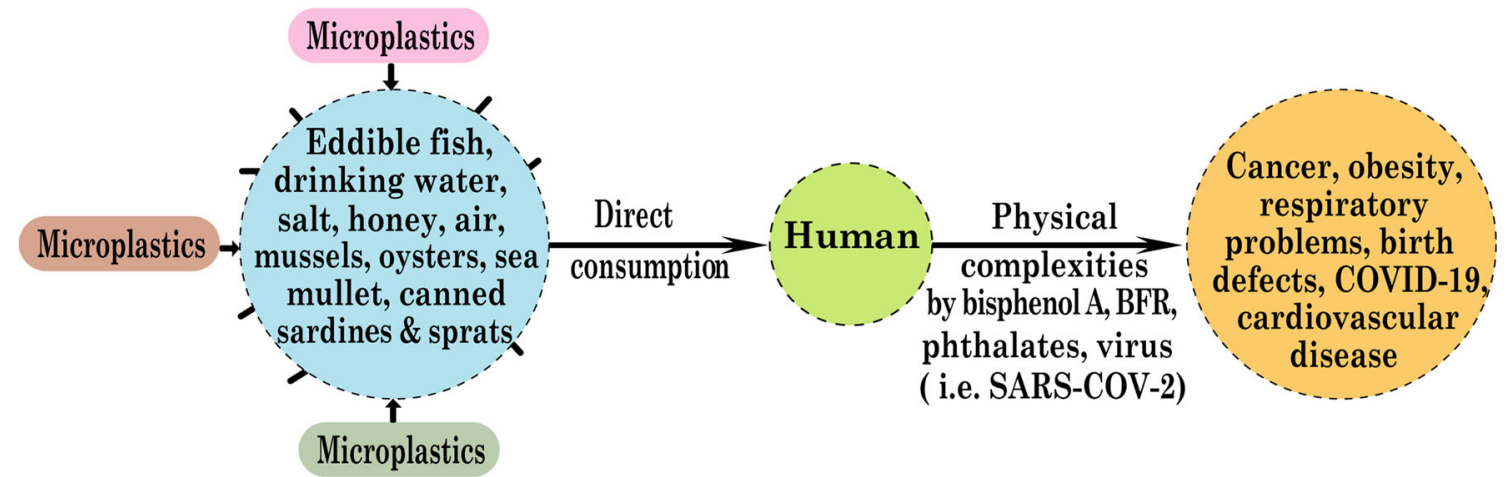

Scheme 3 Impact of microplastics on human health

available in the environment, the most abundant fiber-shaped MPs are found in water ecosystems (Thompson et al. 2004; Claessens et al. 2011). As a result, MPs are embedded in the tissues of aquatic organisms through direct ingestion and the respiration system (Grossman 2015). It is listed that more than 250 marine animals consume MPs, with the majority of vertebrates ingesting (Laist 1997). Among organisms, the death rate of vertebrates is high due to their impulsive nature and is more clearly observed by observers. The impact of plastic particles on marine aquatic organisms is being considered an emerging subject for research activities. Biodiversity research has shown that all sea turtles encounter plastics, half of the total species of sea mammals, and one-fifth of the total species of marine birds. The percentage of the impact of different waste products is also different based on the type of material.

For example, $80 \%$ of the total impact is related to plastic waste, while $11 \%$ is due to microplastics. In contrast, metal $(0.39 \%)$, glass $(0.39 \%)$, and paper waste $(0.64 \%)$ account for about $1.5 \%$ in total. MPs are also ubiquitous in various planktons, sediments, and marine organisms. These particles may be exposed to planktivores, deposit feeders, detritivores, filter feeders, and low trophic suspension (Thompson et al. 2004; Browne et al. 2008; Graham and Thompson 2009; Murray and Cowie 2011). Table 4 summarizes the list of marine organisms encountered by MPs.

A great deal of research work is also available on the use of MPs by vertebrates (Laist 1997; Denuncio et al. 2011; Lazar and Gračan 2011; Van Franeker et al. 2011; Yamashita et al. 2011). MPs can therefore be accumulated in aquatic organisms and cause various physical damages such as peptic ulcers, abrasion in internal or external organs, and GIT clotting (gastrointestinal tract), resulting in false saturation, physical damage, and malnutrition and the resulting deterioration of the reproductive system, obstruction of the feeding tendency, and ingestion of toxic materials from marine environments. These problems are also encountered by various small marine organisms, such as invertebrates. Additional physical damage is also caused by microplastic ingestion, including inhibition of enzyme secretion; toxin adsorption; malnutrition; and reproductive damage resulting in decreased growth rate, minimization of feed stimulus, reduction of hormone levels, delaying egg production from ovaries. Plastic particles are also prone to deposit onto the tissue surface of invertebrates and block the appendices that assist the feeding system (Scheme 4) (Derraik 2002). Also, several factors are more likely to influence both the chemical and physical impact of plastics, including accumulation, translocation, shape, and microplastic excretion (Wright et al. 2013).

\section{Removal of microplastics}

\section{By microorganism}

Microplastic concentrations are rapidly increasing in the biota species (Cole et al. 2013; do Sul and Costa 2014; Neves et al. 2015). These plastic particles are ubiquitous even in the remotest part of the world, such as the deep oceans or the Antarctic Islands (Desforges et al. 2014; Woodall et al. 2014). As a result, the biodegradation of MPs could be a potential solution to eradicate this plastic debris. This process is carried out by micro-organisms, which are more likely to decompose this plastic waste into biomass, methane, carbon dioxide, water, and various inorganic compounds, while the enzymes of organisms play a vital role. Microplastic biodegradations are solely dependent on plastic polymer types with physical and chemical characteristics. Environmental parameters, including sunlight, ultraviolet rays, temperature, and atmospheric humidity, also influence biotic degradation (Shah et al. 2008).

\section{Fungal degradation}

Different fungi can use plastics as their source of nutrients (Russell et al. 2011). As a result, these organisms could potentially be used to degrade MPs. To this end, researchers used marine fungi (Zalerion maritimum) widely available in Portuguese marine waters to degrade PE-based MPs. During the experiments, after 14 days of microplastic exposure to the fungus in controlled media $\left(25^{\circ} \mathrm{C}\right.$, dark environment, 120 - 
Table 4 Microplastic-ingesting marine organisms and their pathways of exposure (Wright et al. 2013)

\begin{tabular}{|c|c|c|c|}
\hline Name of marine organisms & \multicolumn{3}{|c|}{ Pathway of microplastic exposure } \\
\hline Green algae & Marine Algae & adsorption & $\begin{array}{l}\text { Positively charged } \\
\text { nanoplastics }\end{array}$ \\
\hline Microzooplankton & Microzooplankton & ingestion & $\begin{array}{l}\text { Optimum sized } \\
\text { microplastics }\end{array}$ \\
\hline $\begin{array}{l}\text { Deposit feeders or sea cucumber and } \\
\text { lugworm or sandworm }\end{array}$ & $\begin{array}{l}\text { Deposit feeders } \\
\text { and lugworm }\end{array}$ & ingestion & $\begin{array}{l}\text { Sedimented } \\
\text { microplastics/microfibers }\end{array}$ \\
\hline Marine benthic scavenger & $\begin{array}{l}\text { Marine benthic } \\
\text { scavenger }\end{array}$ & ingestion & Sedimented microfibers \\
\hline Mesozooplankton & Mesozooplankton & ingestion & $\begin{array}{l}\text { Microplastics in } \\
\text { water surface }\end{array}$ \\
\hline $\begin{array}{l}\text { Benthic Suspension Feeders like blue } \\
\text { mussel }\end{array}$ & Blue mussel & ingestion & $\begin{array}{l}\text { Submersed microplastics } \\
\text { in water }\end{array}$ \\
\hline
\end{tabular}

rpm continuous stirring), positive correlations were observed as an increase in the percentage of fungus weight with a decrease in the percentage of plastic mass. Here, the biomass variation was $82.0 \% \pm 2.1$, while the plastic mass variation was $56.7 \% \pm 2.9$, and the removal was more than $43 \%$ (Paço et al. 2017). The investigation was also conducted in 2011 to check the potential degradation of PUR MPs by endophytic fungi (Pestalotiopsis microspora). It was noted that serine hydrolase is responsible for the decomposition of this polymer under anaerobic conditions $\left(25^{\circ} \mathrm{C}\right)$, while PUR is considered to be a carbon source (Russell et al. 2011).

Yamada-Onodera and co-workers (Yamada-Onodera et al. 2001) experimented for 3 months to determine the potential for PE degradation of the fungus (Penicillium simplicissimum) and checked molecular weight deterioration from 4000 to 2800. At the same time, Junqing Zhang and co-workers (Zhang et al. 2020) also isolate fungus (Aspergillus flavus) named PEDX3 derived from wax moth or honeycomb moth (Galleria mellonella) intestinal content for PE remediation within 28 days. It was calculated that the mass loss of highdensity polyethylene (HDPE) was $3.9025 \pm 1.18 \%$, as confirmed by the FTIR analysis. Reverse transcriptionpolymerase chain reaction analysis was also conducted to isolate the degradation-responsible enzymes and detect the second oxidizing substrate of laccase-like multi-copper oxidase genes (AFLA 006190 and AFLA 053930). The fungus can degrade MPs within a controlled media at a specific temperature, agitation, and the presence of an enzyme (serine
Scheme 4 Impact of microplastics on aquatic organisms
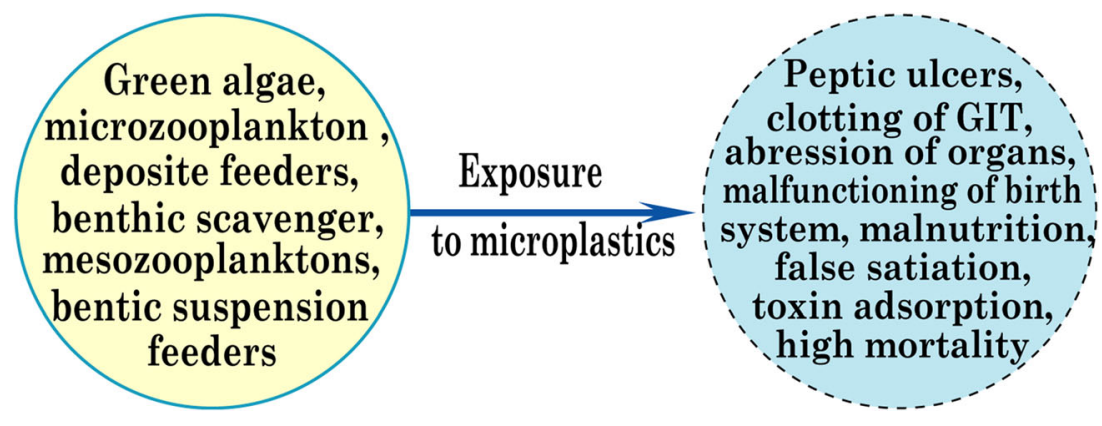
hydrolases). But the plastic degradation time is longer due to the slower reaction rate. Pretreatment is therefore essential to introduce, including solvolysis, ozonolysis, and photo-oxidation, to initiate polymer degradation before fungal degradation.

\section{Bacterial degradation}

Researchers are investigating the potential of different bacteria to degrade MPs into environmentally friendly monomers and could be an emerging alternative to remove plastic debris from the ecosystem. Experiments have been conducted to detect PET degrading whole-cell biocatalysts (Comamonas testosteroni) for the removal of MPs. Three types of media were considered, including bacteria in neutral $\mathrm{pH}$ media $(\mathrm{pH}$ 7), bacteria in alkaline $\mathrm{pH}$ media ( $\mathrm{pH} \mathrm{12)}$, and alkaline media without bacteria. Degradation of PET with bacteria was performed for $48 \mathrm{~h}$, including a temperature of $37^{\circ} \mathrm{C}$ and a stirring rate of $140 \mathrm{rpm}$. The mean PET particle diameter before treatment was $7.3 \mu \mathrm{m}$. After treatment, the particle size was $7.3,2.63$, and $1.58 \mu \mathrm{m}$ for bacteria with no media, neutral $\mathrm{pH}$ media, and alkaline $\mathrm{pH}$ media, respectively. PET degradation rate with biocatalyst in higher $\mathrm{pH}$ is better than neutral media (Gong et al. 2018).

In 2016, research work was also carried out by Shosuke Yoshida and his team members (Yoshida et al. 2016) on the isolation of bacteria (Ideonella sakaiensis, 201-F6) capable of PET degradation into environmentally friendly monomers, TA (terephthalic acid), and ethylene glycol. This bacterium can secrete two enzymes (PETase and MHETase) to hydrolyze PET and use plastic waste as the primary source of carbon nutrients. The PET film degradation rate was $0.13 \mathrm{mg} \mathrm{cm}{ }^{-2}$ per day at a temperature of $30{ }^{\circ} \mathrm{C}$, while $75 \%$ of the decomposed PET film was converted to carbon dioxide at $28{ }^{\circ} \mathrm{C}$. At the same time, another research paper on PE film degradation via bacterium (Bacillus subtilis) was published, which showed that the biosurfactant secretion from this bacterium was responsible for degradation. Low-density polyethylene (LDPE) pretreatment with ultraviolet therapy increased degradation for $72 \mathrm{~h}$ due to increased plastic intake of isolated bacteria (Bacillus subtilis). In these experiments, a weight loss of up to $9.26 \%$ was noted in the presence of biosurfactants within 30 days of incubation of $180 \mathrm{rpm}$ at $32{ }^{\circ} \mathrm{C}$ (Vimala and Mathew 2016). Here, the point to be noted is that microplastic degradation via bacteria is more rapid than fungal activities. Moreover, enzymes and biosurfactants are playing vital role for plastic breakdown. So, pretreatment can also be added here, including photo-induced degradation (photolysis) and chemical degradation before MP exposures under bacteria to minimize degradation time and ensure commercial feasibility.

\section{Marine microalga}

In 2016, researchers found that the bacterium can hydrolyze PET with the PETase enzyme. In addition to this bacterium, Escherichia, as well as Bacillus, both are capable of secreting this PETase enzyme to degrade plastics. Thus, the PETase enzyme plays a vital role in the decomposition of plastics (Huang et al. 2018; Seo et al. 2019). In 2019, Daniel Moog and his colleagues (Moog et al. 2019) isolated a microalga (Phaeodactylum tricornutum) in the marine environment that could secrete PETase enzyme to degrade PET plastics. This enzyme could remain active in a salty environment at a lower temperature $\left(21^{\circ} \mathrm{C}\right)$. It may fragment PET into MHET (2hydroxyethyl terephthalate) and TPA (terephthalic acid) while this microalga has been converted as a potential degradation chassis. As marine microalga can secrete microplastic hydrolyzing enzyme, it may also be worthy to investigate the prospect of freshwater microalga (Chlorophyta, Rhodophyta, Cyanobacteria, Bacillariophyta) to degrade MPs with commercial feasibility.

\section{Periphytic biofilm}

In 2020, Sadaf Shabbir and his co-researchers newly introduced periphytic biofilm (extracellular polymer substances; EPS) to decompose different polymeric MPs such as PET, PE, and PP. Periphytic biofilm was used to detect MPs in the presence of additional nutrients such as glucose and peptone; at the time of the experiments, plastic degradation was measured in weight loss. The batch experiment was conducted in a dark room at $30^{\circ} \mathrm{C}$ and $\mathrm{pH} 7$ for 60 days of incubation. The presence of additional nutrients accelerates the rate of degradation to a moderate limit (about a twofold increase). The use of glucose with biofilm increased the decomposition rate between 13.24 and $19.72 \%$, between 9.52 and $18.02 \%$, and between 5.95 and $14.02 \%$ for PET, PP, and PE, respectively, rather than using periphytic biofilm alone (Shabbir et al. 2020). Hence, the plastic decomposition rate of the periphytic biofilm is still nominal than other decomposition methods. Research should be conducted to investigate more suitable catalysis like polysaccharide starches: sucrose, lactose, and fructose to enhance degradation rate.

\section{By adsorption}

Biosorption could be a promising and innovative technique for extracting MPs from water using adsorbent materials. Biosorption is a simple physicochemical process (Van der Waals force or ion exchange) that causes adsorbate to bind to the surface of adsorbents (Mrvčić et al. 2012). Recent 
studies have shown that the marine algae of Fucus vesiculosus (brown algae) may adsorb MPs due to alginic acid's presence in its cell wall (Sundbæk et al. 2018). The carboxylic functional group is present in brown algae on alginate polymer, and the adsorption capacity of the algae is directly proportional to the availability of these functional groups on the surface. Thus, it can be said that the presence of the carboxylic group is responsible for the plastic binding capacity of the adsorbents.

Research also conducted on removing MPs through the adsorption system and reported that biodegradable, compressive, and porous sponge incorporated with chitin and graphene oxide (ChGO) could absorb different types of plastic particles (Fig. 3). This sponge can be used within three successive cycles of microplastic adsorption and desorption. Here, H-bond, pie, and electrostatic attraction play the primary role of microplastic adsorption on the surface of the graphenemodified adsorbent. In order to confirm biodegradability, the graphene-coated sponge was buried, and, after 3 days, hyphae were found on the surface of the sponge. After 28 days of completion, the sponge was entirely degraded by the soil microorganism and confirmed its biodegradability. Recently, Yuan et al. developed a 3D (three-dimensional)-reduced graphene oxide adsorbent to separate PS-based MPs. In this experiment, stout $\pi-\pi$ bond within benzene moiety of polystyrene and carbon atoms of 3D-reduced graphene oxide plays a vital role for microplastic separation from water.

Moreover, research should be conducted to check this nano adsorbent's reusability to avoid secondary pollution into the environment. Thus, adsorption is a time-consuming and laborintensive process. So, it is challenging to introduce commercially. Moreover, it also responsible for secondary pollution burden and requires special arrangement when going for the landfilling or regeneration for further use. This process can be used as a pretreatment before going for the more advanced tactics like nanomaterial-based membrane system or advanced oxidation system.

\section{By magnetic extraction}

Magnetic extraction is more likely to separate MPs from wastewater, according to the investigation. This method included magnetic seeds ( $\mathrm{Fe}$ nanoparticles), oxalic acid (as $\mathrm{Fe}$ di-sorbent), and external magnetic attraction to separate MPs from seeds. Iron-based nanoparticles have been used due to their ferromagnetic properties, low-cost availability, and more available specific surface area. Hydrophobicity of nanoparticles was ensured by the deposit of hexadecyltrimethoxysilane on the surface of nanoparticles, and this modification allowed the bonding of plastic particles. Almost $92 \%$ of PS and PE beads with a range of 10 to $20 \mu \mathrm{m}$ can be removed.

On the contrary, MPs (PET, PVC, and PP) of a smaller size (less than $1 \mathrm{~mm}$ ) have been removed up to $93 \%$. Besides, 78 and $84 \%$ of medium-sized $(200 \mu \mathrm{m}-1 \mathrm{~mm})$ MPs were removed from the sediment and fresh water, respectively. This method is, therefore, useful for small plastic particles (less than $10 \mu \mathrm{m})$. However, these nanoparticles are not biodegradable and cannot be reused, leading to secondary pollution. Also, the presence of soil particles and lipophilic substances may reduce the plastic removal percentage by damaging nanoparticles (Fig. 4) (Grbic et al. 2019; Shen et al. 2020; Sun et al. 2020). Recently, $\mathrm{TiO}_{2}$-based photocatalytic micromotors are introduced by Wang et al. (2019) to remove MPs in aqueous media. Authors proposed two new processes to extract microplastics while phoretic interaction is incorporated to remove primary microplastics (personal care products) and chains of magnetic micromotor (via shoveling effect) are used to ensure the motility of microplastics under magnetic field for higher segregation. But still, a challenge remained to confirm
Fig. 3 SEM image of $\mathrm{Ch}(\mathbf{a})$, ChGO-50 (b), ChGO-100 (c), and ChGO-300 (d) sponges (Sun et al. 2020)

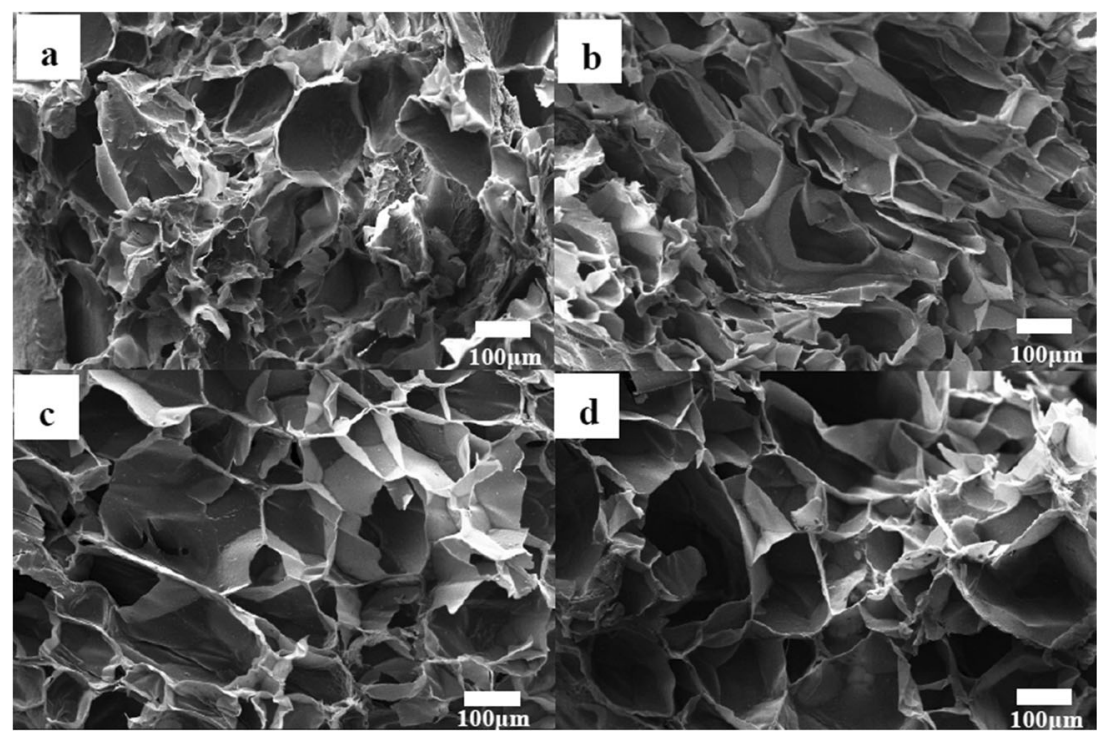


a

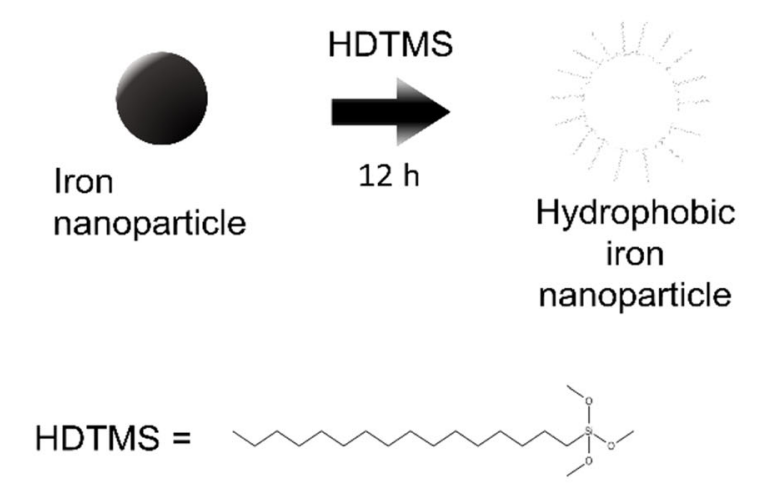

C

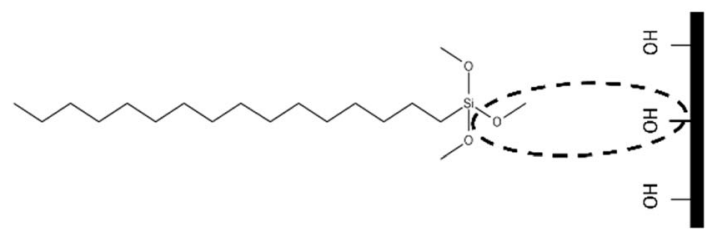

Fig. 4 Schematic of the magnetic plastic separation method. a Modification of $\mathrm{Fe}$ nanoparticles with hexadecyltrimethoxysilane (HDTMS) creates hydrophobic Fe nanoparticles that bind to plastic due to hydrophobic interaction. HDTMS binds to the nanoparticles to create

selectivity as well as recognition of plastic particles by micromotors.

\section{By biofiltration}

Researchers have noted that new wastewater treatment plants are more likely to remove different nutrients and organic matter than MPs. However, more than $90 \%$ of MPs can be removed through these conventional treatment plants. However, a large quantity of MPs is discharged directly into the environment (Carr et al. 2016; Mason et al. 2016; Simon et al. 2018; Gatidou et al. 2019; Sun et al. 2019). In this context, Fan Liu and his co-investigators (Liu et al. 2020) introduced a biofilter to remove MPs from secondary water treatment plant effluents. During this study, a biofilter plant prototype was used to remove MPs from personal beautification products, pharmaceutical waste, and treatment plant effluents. This biofilter was designed with different layers while the secondary effluents entered the top portion of the filter, and the treated effluent was discharged through the bottom. Biofilter was packed with six different thick layers of stone wool $(1.1 \mathrm{~m}$ in total height). Before treatment, the effluent contained 917 particles $/ \mathrm{m}^{3}$ with $24.8 \mu \mathrm{g} / \mathrm{m}^{3}$, whereas, after treatment with a biofilter, the particulate matter was reduced to 197 particles/ $\mathrm{m}^{3}(79 \%)$ with a mass concentration of $2.8 \mu \mathrm{g} / \mathrm{m}^{3}(89 \%)$. This biofilter is more likely to encounter large MPs $(>100 \mu \mathrm{m})$ with a higher mass concentration than small ones. Thus, with this limitation, complete removal cannot be ensured.
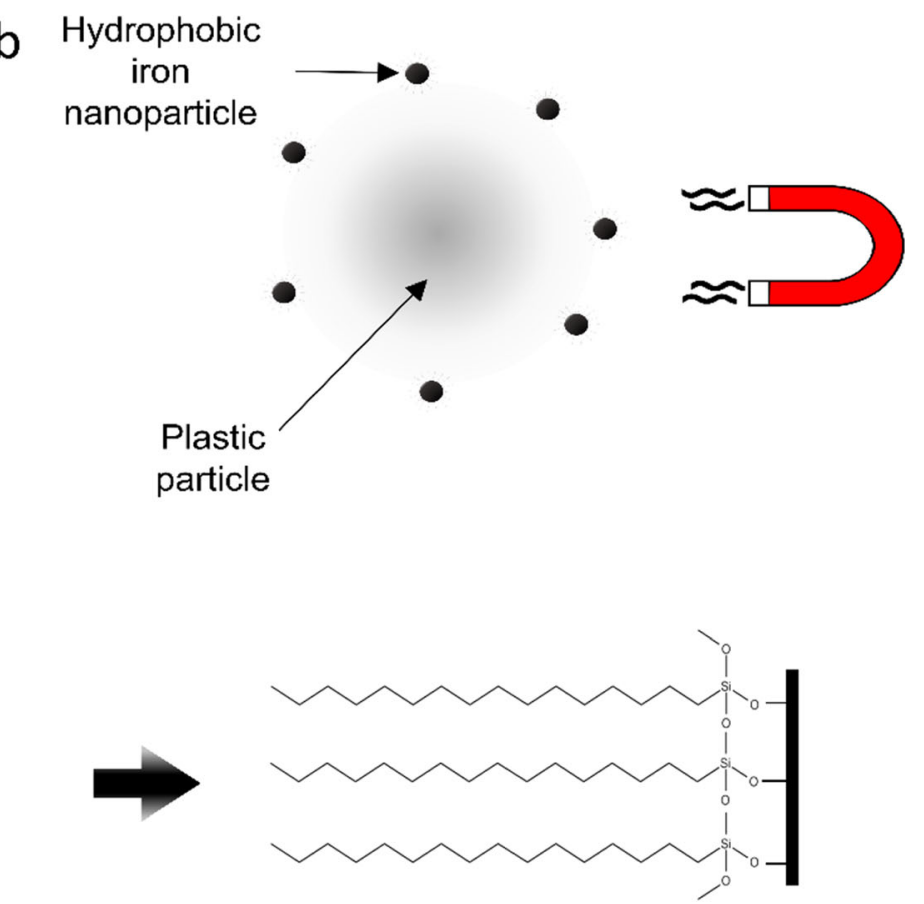

hydrophobic tails. b Bound Fe nanoparticles allow magnetic recovery of MPs because magnetic force acts on the particles. $\mathbf{c}$ Pictorial representation of HDTMS bonding to $\mathrm{OH}$ groups on the native oxide layer of $\mathrm{Fe}$ (Grbic et al. 2019)

\section{By membrane filtration}

Various treatment processes are available to remove MPs, including sedimentation, skimming, and a variety of advanced tertiary level filtration systems. But none of them is dedicated solely to the removal of MPs. As a matter of principle, the development of microplastic removal technology is still at the preliminary stage of research. Although many water treatment plants are used to separate MPs, many plastic particles are still entering the aquatic ecosystem through sludge management and effluent discharge (Sun et al. 2019). Various researchers investigated the efficacy of the microplastic removal using different membranes as a tertiary level of the treatment system. At this level, membrane filtration is a physical barrier to extract plastic particles from water, although not intended for plastic removal. Above all, membranes can remove MPs from the water system with higher efficiency and some advantages, such as stable effluent quality and ease of treatment (Baker 2012; Park et al. 2017; Talvitie et al. 2017a, b). Comparing with different tertiary level treatment efficacy such as rapid sand filter, disk filter, and dissolved air flotation refining secondary effluent with 97, 98.5, and 95\% removal efficiency, respectively, the membrane bioreactor encounters primary effluent with $99.9 \%$ efficiency. MPs can also be removed by reverse osmosis as well as by ultrafiltration. On the contrary, advanced granular separation systems and active biological filters have not deduced plastic concentrations in water treatment plants (Mason et al. 2016; Talvitie et al. 2017a, b). 
Research has shown that smaller plastic particles (20-190 $\mu \mathrm{m})$ and fiber-shaped MPs are so stubborn to remove even after tertiary treatment. This may be due to the longitudinal migration of the fibers and particles through the membrane's pores (Michielssen, Michielssen et al. 2016, Ziajahromi et al. 2017).

In addition to rapid filtration, a gravitational-powered system was introduced to extract secondary MPs with two operating moods. One is the microplastic filtration mood of the wastewater, and the other is the back flush to wash the particles out of the system. The effect of transmembrane pressure, flow rate, filtration materials, and plastic recovery has also been studied, and a pressure of $1.68 \mathrm{kPa}$ ensured the best removal performance. The dynamic membrane filtration system has also been energy-saving exposed to encountering MPs. However, the development, as well as the operating unit cost first, should be considered before going to the additional unit in the treatment plant for removal of MPs ( $\mathrm{Li}$ et al. 2018c; Sun et al. 2019). In addition to higher removal efficiency, membrane filtration is associated with severe membrane fouling problems. So, before moving on to membrane technology, a strategy should be put in place to address this clogging problem. During wastewater treatment, macromolecules and particles, including MPs, interact with membrane materials both physically and chemically and are deposited on the membrane surface or in membrane pores. As a result, these unwanted depositions squeeze the membrane's pores, resulting in the clogging of the membrane (Enfrin et al. 2019). Several impacts are observed due to this clogging, such as reduced water flow; higher transmembrane pressure; and higher energy, maintenance costs, and operating time. In general, membrane pore sizes are smaller than MPs, and a large number of plastic particles $\left(10^{6}-10^{7}\right)$ interact with the membrane surface every day in water treatment plants. This frequent interaction reduces both pore size and filtration performance at the same time (Ma et al. 2019). Researchers have assumed that different treatment levels in water treatment plants have made MPs more likely to cause further fragmentation and result in nanoplastic particles. Regarding this issue, Enfrin et al. (Enfrin et al. 2020) recently investigated the effect of shear stress forces on MPs during the pumping of wastewater. The study highlighted that MPs are fragmented via turbulence of pumping into nanoplastics, and the whole phenomena are governed by crack propagation mechanism. So, these fragments are highly prone to deposit on the membrane surface, and micro-organisms are also more likely to settle on the plastic surface through biofilm formation, while these MPs act as potential vectors. As a result, these types of deposition and film formations ultimately cause biofouling of the membrane (Fig. 5) (Enfrin et al. 2019; Iorhemen et al. 2016). Due to the lack of sufficient research, the phenomenon of membrane fouling by MPs is not yet clear to understand, although Enfrin investigated the mechanism of membrane fouling by microplastics/nanoplastics in the crossflow filtration system. Their study highlighted the effect of surface charge and the electrostatic interaction between membrane surface and plastic particles on fouling phenomena. Based on their explanation, adsorption of plastic particles on membrane surface and membrane pores (cake layer formation) is responsible for membrane clogging rather than internal pore blocking. So, further research on robust antifouling tactics like active antifouling strategies as well as passive antifouling strategies should be carried out to ensure longer filtration properties. However, some actions during water treatment can minimize fouling problems, including the selection of optimized pretreatment and wastewater treatment systems, the efficient and rapid membrane backwashing system.

In addition, the selection of membrane materials on the basis of selectivity and permeability can lead to a reduction in fouling, and this material development should be compatible with the characteristics of MPs. Research has shown that microplastic has become negatively charged in aquatic environments. Thus, if it is possible to develop a membrane material surface with a negatively charged functional group, negatively charged microplastic may be rejected during treatment operations, and the fouling problem may be minimized to a greater extent (Fotopoulou and Karapanagioti 2012; Enfrin et al. 2019; Shen et al. 2020).

\section{By electrocoagulation}

In addition to microbial degradation and chemical coagulation, electrocoagulation is a treatment process in which cations are formed by metal electrodes in the electrical field. It produces coagulants using metal electrodes that are more likely to encounter MPs with several advantages, including sludge minimization, automatic treatment, and efficient and low operating costs. This process was also used for the removal of PE-based MPs (300-355 $\mu \mathrm{m})$. During the experiments, a higher removal percentage (99.24\%) was observed at $\mathrm{pH} 7.5$ and current density 11 $\mathrm{A} / \mathrm{m}^{2}$ due to higher coagulant formation at this neutral $\mathrm{pH}$. It was also noted that maximum efficiency was achieved after $40 \mathrm{~min}$ of operation, and a gradual increase in current density did not result in higher removal performance. Besides, water conductivity has shown no effect on removal efficacy. The operating cost for the removal of MPs has also been calculated and summarized that electrocoagulation can provide higher efficiency at a lower cost than further removal of pollutants (Perren et al. 2018). This process can therefore be used in a commercial format for encountering MPs before discharge into the aquatic environment. 


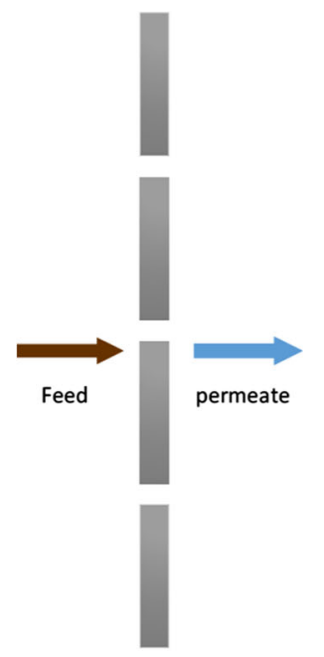

(a) New membrane

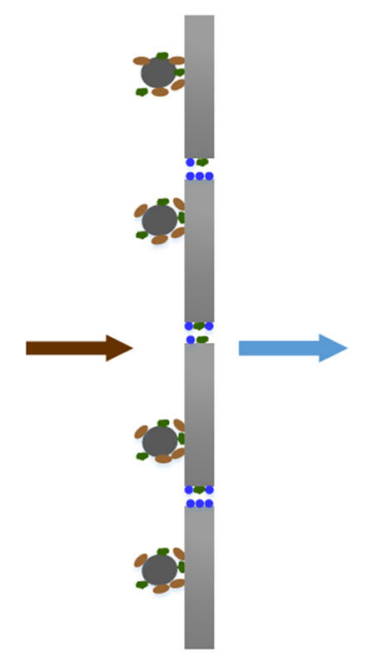

(b) Pore narrowing

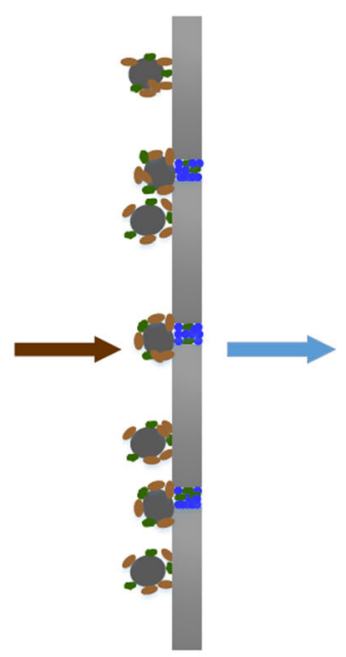

(c) Pore clogging

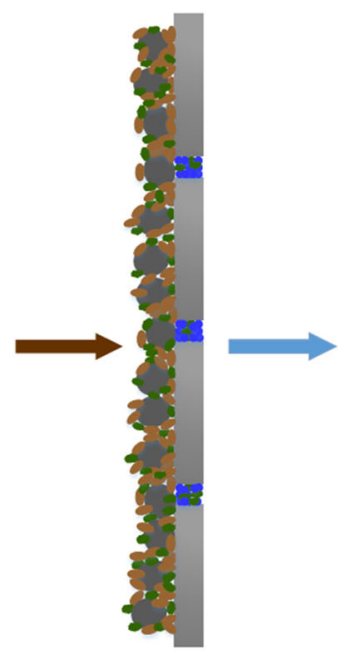

(d) Cake formation

Fig. 5 Mechanisms of membrane fouling in membrane bioreactors (MBR) (Iorhemen et al. 2016)

\section{By chemical coagulation}

Various conventional chemical coagulates are used for this removal purpose to find alternative solutions for the removal of MPs. In the water treatment field, coagulants such as different iron salts $\left(\mathrm{Fe}_{2}\left(\mathrm{SO}_{4}\right)_{3} \cdot 9 \mathrm{H}_{2} \mathrm{O}, \mathrm{FeCl}_{3} \cdot 6 \mathrm{H}_{2} \mathrm{O}\right)$ and aluminum salts $\left(\mathrm{KAl}\left(\mathrm{SO}_{4}\right)_{2} \cdot 12 \mathrm{H}_{2} \mathrm{O}, \mathrm{AlCl}_{3} \cdot 6 \mathrm{H}_{2} \mathrm{O}, \mathrm{Al}_{2}\left(\mathrm{SO}_{4}\right)_{3} \cdot 18 \mathrm{H}_{2} \mathrm{O}\right)$ are used to capture dissolved solids in wastewater by forming flocculants and to settle them at the bottom of the coagulation tank. Various parameters, including the $\mathrm{pH}$ of wastewater, the concentrations of pollutants, and the surface charge, are also associated with this process (Jamal et al. 2019). MPs are negatively charged in aquatic media and can be removed by chemical coagulation. Researchers have reported that coagulation or flocculation may be used to encounter MPs before discharging into the ecosystem. However, further investigations are needed to optimize this process to improve the efficacy of removal. During experiments, aluminum-based coagulants with polyacrylamide incorporation performed better than iron-based coagulants with removal performance (Fotopoulou and Karapanagioti 2012; Ma et al. 2019; Triebskorn et al. 2019).

In the search for sustainable technology to remove MPs, the agglomeration method has been introduced by researchers to separate PE and PP microplastics from the aquatic environment. A physicochemical process was used by using alkoxysilanes (tetraethoxysilane) to aggregate these plastic particles through the formation of alkoxysilyl bond and then extracted by conventional sand filtration system (Herbort et al. 2018).

The development of microplastic removal technology is in the primary stage, and there is no reliable method yet established on a commercial scale. Different conventional treatment technologies are being utilized, while a vast quantity of MPs is draining out through treatment plants' effluent (Fig. 6). Also, these conventional processes may, to some extent, remove MPs but also be responsible for secondary microplastic pollution. So, recycling of the treatment system is worthy of investigation, and simultaneously, the final disposal of this treatment media is also notable to analysis. Specifically, microbial degradation can decompose MPs, but the degradation rate is too slow to make it industrially feasible. In this case, the chemical degradation process should be incorporated to accelerate decomposition before microbial treatment.

Moreover, magnetic extraction, adsorption, chemical, and electrocoagulation are promising, but they are limited in use due to longer contact time, chemical consumption, and lower removal rate. In this phenomenon, hybrid treatment technology should be incorporated for the complete removal of MPs from wastewater. The incorporation of microbial treatment with membrane technology is highly promising. Still, it is worth mentioning to investigate the impact of operational conditions, including membrane surface charge, membrane material, fouling phenomena, transmembrane pressure, pore size, and hydraulic retention time to MPs removal. On the other hand, investigation on sample pretreatment (ozonolysis, solvolysis) is also notable before going for microbe's hybridization utilization to ensure maximum removal rate.

\section{Conclusions and recommendations}

The establishment of standard methods for microplastic detection and removal remains a challenge due to variations in their characteristics and uncertainty in complete eradication from the environment. In this review, critical analysis is carried out regarding the evolution and impact of conventional and newly 
Fig. 6 Evolution and impact of microplastic removal methods

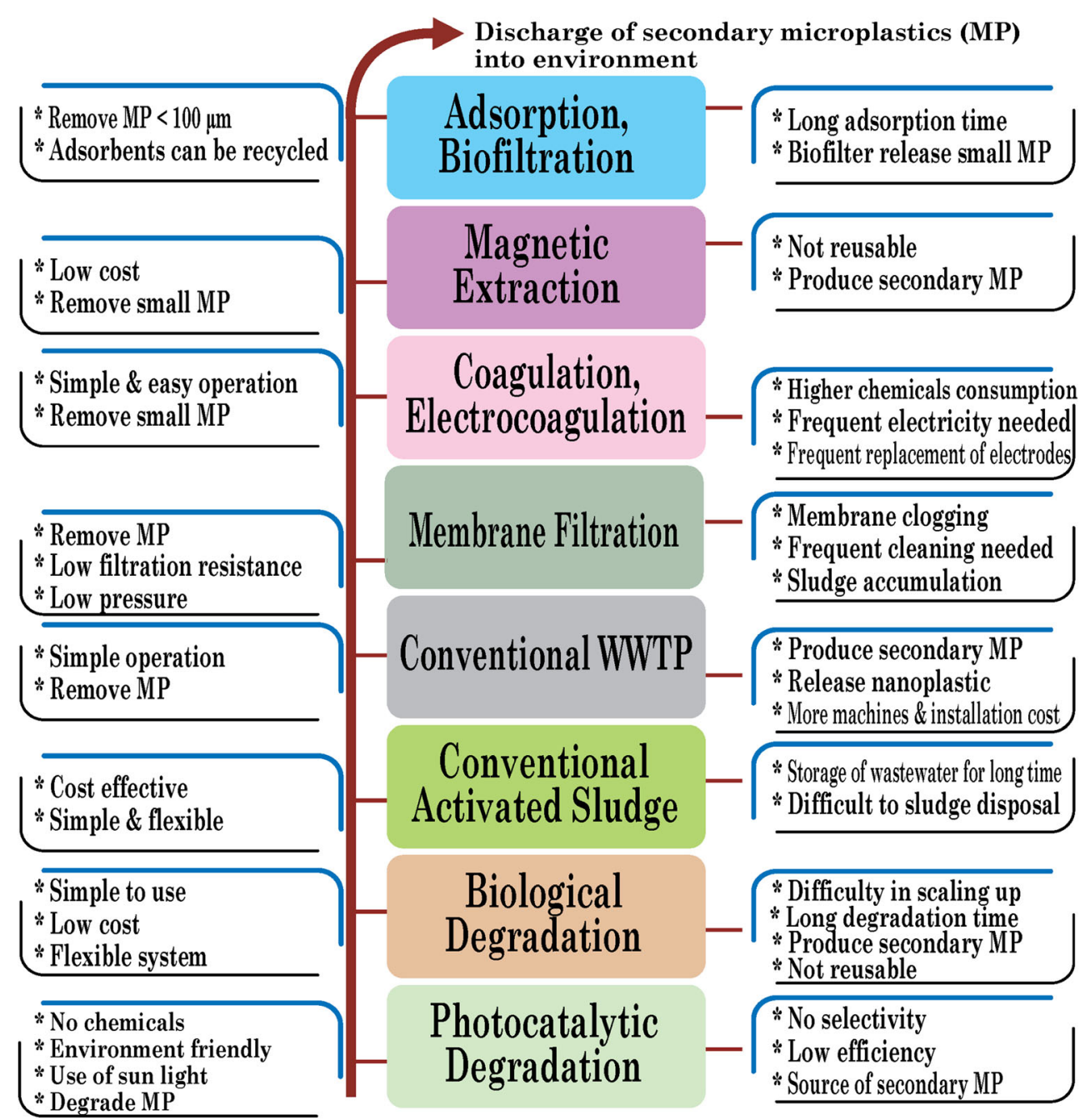

incorporated MP detection and removal techniques. In terms of the evolution in microplastic detection, the single-stage detection method was initially considered, while unaided eyes with forceps were used to detect various MPs. But to minimize both processes error and labor intensity, the genesis of stereomicroscope was noticed. Due to size limitation and error in the discrepancy of microplastic's color and composition, central laboratory methods, such as SEM-EDX and PLM, become famous for this purpose. Again, considering cost, portability, and user-friendliness, FTIR is being used frequently. However, to enhance the dimension of investigations, FPAFTIR, TGA-FTIR, and Raman are doing the job of detecting MPs in the environment. Also, researchers are now thinking about using remote sensing as a preliminary screening of MPs.

In the microplastic removal strategy, most conventional sewage treatment plants are being used to handle microplastic pollution. To improve the efficiency, pretreatment with photocatalytic and biological degradation would reduce the microplastic release in the environment. Traditionally, activated sludge is also used to separate MPs, but the disposal of sludge was a significant sustainability problem. Membrane filtration is mostly promising until now, at which the maximum amount of removal is noticed in recent studies. But it is also convoluted with membrane fouling issues. Work is in progress with incorporating electrocoagulation, magnetic extraction, and adsorption chronologically in the removal process. However, higher energy consumption, secondary microplastic pollution, and longer time duration limit the commercial use of these techniques. Microplastics based on polystyrene (PE) and polyethylene (PE) are commonly found in the environment, mainly from the garment and household utensils, respectively. Source segregation on sites and awareness-raising campaigns should be carried out through the local authority to reduce MPs in both wastewater and surface water. Consideration should also be given to the development of membrane-based antifouling technology as a further research area that would allow removing MP pollution from water.

Author contribution TKD analyzed and interpreted the evolution and impact of microplastics detection and removal. MEU explained the impact of microplastics on living beings. MJ analyzed, interpreted the evolution and impact of microplastics detection and removal, and explained 
the impact of microplastics on living beings. All authors participated in writing the manuscript and read and approved the final manuscript.

Funding This work was financially supported by the Ministry of Science \& Technology (special research allocation fund 2019-2020) and the University Grant Commission, Bangladesh.

Data availability Not applicable

\section{Declarations}

Ethics approval and consent to participate Not applicable

Consent for publication Not applicable

Competing interests The three authors declare no competing interests.

\section{References}

Acosta-Coley I, Olivero-Verbel J (2015) Microplastic resin pellets on an urban tropical beach in Colombia. Environ Monit Assess 187(7): 435

Anderson A, Grose J, Pahl S, Thompson R, Wyles KJ (2016) Microplastics in personal care products: exploring perceptions of environmentalists, beauticians and students. Mar Pollut Bull 113(1-2):454-460

Araujo CF, Nolasco MM, Ribeiro AM, Ribeiro-Claro PJ (2018) Identification of microplastics using Raman spectroscopy: latest developments and future prospects. Water Res 142:426-440

Arthur, C., J. E. Baker and H. A. Bamford (2009). "Proceedings of the International Research Workshop on the Occurrence, Effects, and Fate of Microplastic Marine Debris, September 9-11, 2008, University of Washington Tacoma, Tacoma, WA, USA."

Baalkhuyur FM, Dohaish E-JAB, Elhalwagy ME, Alikunhi NM, AlSuwailem AM, Røstad A, Coker DJ, Berumen ML, Duarte CM (2018) Microplastic in the gastrointestinal tract of fishes along the Saudi Arabian Red Sea coast. Mar Pollut Bull 131:407-415

Baker R (2012) Ultrafiltration. In: Membrane Technology and Applications, 3rd edn. Wiley, Chichester

Bessa, F., P. Barría, J. M. Neto, J. P. Frias, V. Otero, P. Sobral and J. C. Marques (2018). Microplastics in juvenile commercial fish from an estuarine environment. Proceedings of the International Conference on Microplastic Pollution in the Mediterranean Sea, Springer

Biermann L, Clewley D, Martinez-Vicente V, Topouzelis K (2020) Finding plastic patches in coastal waters using optical satellite data. Sci Rep 10(1):1-10

Blair RM, Waldron S, Phoenix VR, Gauchotte-Lindsay C (2019) Microscopy and elemental analysis characterisation of microplastics in sediment of a freshwater urban river in Scotland, UK. Environ Sci Pollut Res 26(12):12491-12504

Bråte ILN, Eidsvoll DP, Steindal CC, Thomas KV (2016) Plastic ingestion by Atlantic cod (Gadus morhua) from the Norwegian coast. Mar Pollut Bull 112(1-2):105-110

Browne MA, Dissanayake A, Galloway TS, Lowe DM, Thompson RC (2008) Ingested microscopic plastic translocates to the circulatory system of the mussel, Mytilus edulis (L.). Environ Sci Technol 42(13):5026-5031

Browne MA, Crump P, Niven SJ, Teuten E, Tonkin A, Galloway T, Thompson R (2011) Accumulation of microplastic on shorelines worldwide: sources and sinks. Environ Sci Technol 45(21):91759179
Carr SA, Liu J, Tesoro AG (2016) Transport and fate of microplastic particles in wastewater treatment plants. Water Res 91:174-182

Catarino AI, Macchia V, Sanderson WG, Thompson RC, Henry TB (2018) Low levels of microplastics (MP) in wild mussels indicate that MP ingestion by humans is minimal compared to exposure via household fibres fallout during a meal. Environ Pollut 237:675-684

Cesa FS, Turra A, Baruque-Ramos J (2017) Synthetic fibers as microplastics in the marine environment: a review from textile perspective with a focus on domestic washings. Sci Total Environ 598: $1116-1129$

Cipelli R, Harries L, Okuda K, Yoshihara SI, Melzer D, Galloway T (2014) Bisphenol A modulates the metabolic regulator oestrogenrelated receptor- $\alpha$ in T-cells. Reproduction (Cambridge, England) 147(4):419-426

Claessens M, De Meester S, Van Landuyt L, De Clerck K, Janssen CR (2011) Occurrence and distribution of microplastics in marine sediments along the Belgian coast. Mar Pollut Bull 62(10):2199-2204

Cole M, Lindeque P, Halsband C, Galloway TS (2011) Microplastics as contaminants in the marine environment: a review. Mar Pollut Bull 62(12):2588-2597

Cole M, Lindeque P, Fileman E, Halsband C, Goodhead R, Moger J, Galloway TS (2013) Microplastic ingestion by zooplankton. Environ Sci Technol 47(12):6646-6655

Cole M, Lindeque PK, Fileman E, Clark J, Lewis C, Halsband C, Galloway TS (2016) Microplastics alter the properties and sinking rates of zooplankton faecal pellets. Environ Sci Technol 50(6): 3239-3246

Compa M, Ventero A, Iglesias M, Deudero S (2018) Ingestion of microplastics and natural fibres in Sardina pilchardus (Walbaum, 1792) and Engraulis encrasicolus (Linnaeus, 1758) along the Spanish Mediterranean coast. Mar Pollut Bull 128:89-96

Cooper DA, Corcoran PL (2010) Effects of mechanical and chemical processes on the degradation of plastic beach debris on the island of Kauai, Hawaii. Mar Pollut Bull 60(5):650-654

Dazzi A, Saunier J, Kjoller K, Yagoubi N (2015) Resonance enhanced AFM-IR: A new powerful way to characterize blooming on polymers used in medical devices. Int J Pharm 484(1-2):109-114

Dekiff JH, Remy D, Klasmeier J, Fries E (2014) Occurrence and spatial distribution of microplastics in sediments from Norderney. Environ Pollut 186:248-256

De-la-Torre GE (2019) Microplastics: an emerging threat to food security and human health. J Food Sci Technol:1-8

Denuncio P, Bastida R, Dassis M, Giardino G, Gerpe M, Rodríguez D (2011) Plastic ingestion in Franciscana dolphins, Pontoporia blainvillei (Gervais and d'Orbigny, 1844), from Argentina. Mar Pollut Bull 62(8):1836-1841

Derraik JG (2002) The pollution of the marine environment by plastic debris: a review. Mar Pollut Bull 44(9):842-852

Desforges J-PW, Galbraith M, Dangerfield N, Ross PS (2014) Widespread distribution of microplastics in subsurface seawater in the NE Pacific Ocean. Mar Pollut Bull 79(1-2):94-99

Di M, Wang J (2018) Microplastics in surface waters and sediments of the Three Gorges Reservoir, China. Sci Total Environ 616:1620-1627

do Sul JAI, Costa MF (2014) The present and future of microplastic pollution in the marine environment. Environ Pollut 185:352-364

Dris R, Gasperi J, Mirande C, Mandin C, Guerrouache M, Langlois V, Tassin B (2017) A first overview of textile fibers, including microplastics, in indoor and outdoor environments. Environ Pollut 221:453-458

Dümichen E, Barthel A-K, Braun U, Bannick CG, Brand K, Jekel M, Senz R (2015) Analysis of polyethylene microplastics in environmental samples, using a thermal decomposition method. Water Res $85: 451-457$

Dümichen E, Eisentraut P, Bannick CG, Barthel A-K, Senz R, Braun U (2017) Fast identification of microplastics in complex 
environmental samples by a thermal degradation method. Chemosphere 174:572-584

Elert AM, Becker R, Duemichen E, Eisentraut P, Falkenhagen J, Sturm H, Braun U (2017) Comparison of different methods for MP detection: what can we learn from them, and why asking the right question before measurements matters? Environ Pollut 231:1256-1264

Enfrin M, Dumée LF, Lee J (2019) Nano/microplastics in water and wastewater treatment processes - Origin, impact and potential solutions. In: Nano/microplastics in water and wastewater treatment processes-origin, impact and potential solutions. Research, Water

Enfrin M, Lee J, Gibert Y, Basheer F, Kong L, Dumée LFJJ o h m (2020) Release of hazardous nanoplastic contaminants due to microplastics fragmentation under shear stress forces. Hazard Mater 384:121393

Enyoh CE, Wirnkor VA, Ngozi VE (2020) Novel coronavirus (SARSCoV-2) and airborne microplastics. Zenodo

Eriksen M, Lebreton LC, Carson HS, Thiel M, Moore CJ, Borerro JC, Galgani F, Ryan PG, Reisser J (2014) Plastic pollution in the world's oceans: more than 5 trillion plastic pieces weighing over 250,000 tons afloat at sea. PLoS One 9(12):e111913

Erni-Cassola G, Gibson MI, Thompson RC, Christie-Oleza JA (2017) Lost, but found with Nile Red: a novel method for detecting and quantifying small microplastics (1 $\mathrm{mm}$ to $20 \mu \mathrm{m}$ ) in environmental samples. Environ Sci Technol 51(23):13641-13648

Europe, P. (2017). Plastics - the facts 2015 an analysis of European plastics production, demand and waste data, Available on the website: http://www.plasticseurope.org.

Fabbri D (2001) Use of pyrolysis-gas chromatography/mass spectrometry to study environmental pollution caused by synthetic polymers: a case study: the Ravenna Lagoon. J Anal Appl Pyrolysis 58:361-370

Fabbri D, Tartari D, Trombini C (2000) Analysis of poly (vinyl chloride) and other polymers in sediments and suspended matter of a coastal lagoon by pyrolysis-gas chromatography-mass spectrometry. Anal Chim Acta 413(1-2):3-11

Faure F, Demars C, Wieser O, Kunz M, De Alencastro LF (2015) Plastic pollution in Swiss surface waters: nature and concentrations, interaction with pollutants. Environ Chem 12(5):582-591

Fotopoulou KN, Karapanagioti HK (2012) Surface properties of beached plastic pellets. Mar Environ Res 81:70-77

Fries E, Dekiff JH, Willmeyer J, Nuelle M-T, Ebert M, Remy D (2013) Identification of polymer types and additives in marine microplastic particles using pyrolysis-GC/MS and scanning electron microscopy. Environ Sci Process Impacts 15(10):1949-1956

Galgani F, Hanke G, Werner S, De Vrees L (2013) Marine litter within the European marine strategy framework directive. ICES J Mar Sci 70(6):1055-1064

Gatidou G, Arvaniti OS, Stasinakis AS (2019) Review on the occurrence and fate of microplastics in sewage treatment plants. J Hazard Mater 367:504-512

Gómez C, Gallart-Ayala H (2018) Metabolomics: a tool to characterize the effect of phthalates and bisphenol A. Environ Rev 26(4):351357

Gong J, Kong T, Li Y, Li Q, Li Z, Zhang J (2018) Biodegradation of microplastic derived from poly (ethylene terephthalate) with bacterial whole-cell biocatalysts. Polymers 10(12):1326

Graham ER, Thompson JT (2009) Deposit-and suspension-feeding sea cucumbers (Echinodermata) ingest plastic fragments. J Exp Mar Biol Ecol 368(1):22-29

Grbic J, Nguyen B, Guo E, You JB, Sinton D, Rochman CM (2019) Magnetic extraction of microplastics from environmental samples. Environ Sci Technol Lett 6(2):68-72

Grossman E (2015) How plastics from your clothes can end up in your fish. TIME, USA

Gu J-D (2003) Microbiological deterioration and degradation of synthetic polymeric materials: recent research advances. Int Biodeterior Biodegradation 52(2):69-91
Guart A, Wagner M, Mezquida A, Lacorte S, Oehlmann J, Borrell A (2013) Migration of plasticisers from Tritan ${ }^{\mathrm{TM}}$ and polycarbonate bottles and toxicological evaluation. Food Chem 141(1):373-380

Halstead JE, Smith JA, Carter EA, Lay PA, Johnston EL (2018) Assessment tools for microplastics and natural fibres ingested by fish in an urbanised estuary. Environ Pollut 234:552-561

Harrison JP, Ojeda JJ, Romero-González ME (2012) The applicability of reflectance micro-Fourier-transform infrared spectroscopy for the detection of synthetic microplastics in marine sediments. Sci Total Environ 416:455-463

Heo NW, Hong SH, Han GM, Hong S, Lee J, Song YK, Jang M, Shim WJ (2013) Distribution of small plastic debris in cross-section and high strandline on Heungnam beach, South Korea. Ocean Sci J 48(2):225-233

Herbort AF, Sturm MT, Schuhen K (2018) A new approach for the agglomeration and subsequent removal of polyethylene, polypropylene, and mixtures of both from freshwater systems-a case study. Environ Sci Pollut Res 25(15):15226-15234

Hidalgo-Ruz V, Thiel M (2013) Distribution and abundance of small plastic debris on beaches in the SE Pacific (Chile): a study supported by a citizen science project. Mar Environ Res 87:12-18

Hidalgo-Ruz V, Gutow L, Thompson RC, Thiel M (2012) Microplastics in the marine environment: a review of the methods used for identification and quantification. Environ Sci Technol 46(6):3060-3075

Hintersteiner I, Himmelsbach M, Buchberger WW (2015) Characterization and quantitation of polyolefin microplastics in personal-care products using high-temperature gel-permeation chromatography. Anal Bioanal Chem 407(4):1253-1259

Hirai H, Takada H, Ogata Y, Yamashita R, Mizukawa K, Saha M, Kwan C, Moore C, Gray H, Laursen D (2011) Organic micropollutants in marine plastics debris from the open ocean and remote and urban beaches. Mar Pollut Bull 62(8):1683-1692

Horton AA, Svendsen C, Williams RJ, Spurgeon DJ, Lahive E (2017) Large microplastic particles in sediments of tributaries of the River Thames, UK-Abundance, sources and methods for effective quantification. Mar Pollut Bull 114(1):218-226

Huang X, Cao L, Qin Z, Li S, Kong W, Liu Y (2018) Tat-independent secretion of polyethylene terephthalate hydrolase PETase in Bacillus subtilis 168 mediated by its native signal peptide. J Agric Food Chem 66(50):13217-13227

Iñiguez ME, Conesa JA, Fullana A (2017) Microplastics in Spanish table salt. Sci Rep 7(1):1-7

Iorhemen OT, Hamza RA, Tay JH (2016) Membrane bioreactor (MBR) technology for wastewater treatment and reclamation: membrane fouling. Membranes 6(2):33

Jabeen K, Su L, Li J, Yang D, Tong C, Mu J, Shi H (2017) Microplastics and mesoplastics in fish from coastal and fresh waters of China. Environ Pollut 221:141-149

Jamal M, Sarac AS, Magner E (2004) Conductive copolymer-modified carbon fibre microelectrodes: electrode characterisation and electrochemical detection of p-aminophenol. Sensors Actuators B Chem 97(1):59-66

Jamal M, Razeeb KM, Shao H, Islam J, Akhter I, Furukawa H, Khosla A (2019) Development of tungsten oxide nanoparticle modified carbon fibre cloth as flexible $\mathrm{pH}$ sensor. Sci Rep 9(1):4659

Jani P, Halbert GW, LANGRIDGE J, Florence AT (1990) Nanoparticle uptake by the rat gastrointestinal mucosa: quantitation and particle size dependency. J Pharm Pharmacol 42(12):821-826

Jin L, Zhang G, Tian H (2014) Current state of sewage treatment in China. Water Res 66:85-98

Kampf G, Todt D, Pfaender S, Steinmann E (2020) Persistence of coronaviruses on inanimate surfaces and their inactivation with biocidal agents. J Hosp Infect 104(3):246-251

Karami A, Golieskardi A, Ho YB, Larat V, Salamatinia B (2017) Microplastics in eviscerated flesh and excised organs of dried fish. Sci Rep 7(1):1-9 
Karami A, Golieskardi A, Choo CK, Larat V, Karbalaei S, Salamatinia B (2018) Microplastic and mesoplastic contamination in canned sardines and sprats. Sci Total Environ 612:1380-1386

Katija K, Choy CA, Sherlock RE, Sherman AD, Robison BH (2017) From the surface to the seafloor: how giant larvaceans transport microplastics into the deep sea. Sci Adv 3(8):e1700715

Koelmans AA, Besseling E, Foekema EM (2014) Leaching of plastic additives to marine organisms. Environ Pollut 187:49-54

Kolandhasamy P, Su L, Li J, Qu X, Jabeen K, Shi H (2018) Adherence of microplastics to soft tissue of mussels: a novel way to uptake microplastics beyond ingestion. Sci Total Environ 610:635-640

Kowalski N, Reichardt AM, Waniek JJ (2016) Sinking rates of microplastics and potential implications of their alteration by physical, biological, and chemical factors. Mar Pollut Bull 109(1):310 319

Laist DW (1997) Impacts of marine debris: entanglement of marine life in marine debris including a comprehensive list of species with entanglement and ingestion records. Marine Debris, Springer, pp 99-139

Lambert S, Wagner M (2016) Formation of microscopic particles during the degradation of different polymers. Chemosphere 161:510-517

Lambert S, Scherer C, Wagner M (2017) Ecotoxicity testing of microplastics: Considering the heterogeneity of physicochemical properties. Integr Environ Assess Manag 13(3):470-475

Lang IA, Galloway TS, Scarlett A, Henley WE, Depledge M, Wallace RB, Melzer D (2008) Association of urinary bisphenol A concentration with medical disorders and laboratory abnormalities in adults. Jama 300(11):1303-1310

Lares M, Ncibi MC, Sillanpää M, Sillanpää M (2018) Occurrence, identification and removal of microplastic particles and fibers in conventional activated sludge process and advanced MBR technology. Water Res 133:236-246

Law KL, Morét-Ferguson SE, Goodwin DS, Zettler ER, DeForce E, Kukulka T, Proskurowski G (2014) Distribution of surface plastic debris in the eastern Pacific Ocean from an 11-year data set. Environ Sci Technol 48(9):4732-4738

Lazar B, Gračan R (2011) Ingestion of marine debris by loggerhead sea turtles, Caretta caretta, in the Adriatic Sea. Mar Pollut Bull 62(1): 43-47

Li J, Yang D, Li L, Jabeen K, Shi H (2015) Microplastics in commercial bivalves from China. Environ Pollut 207:190-195

Li WC, Tse H, Fok L (2016) Plastic waste in the marine environment: a review of sources, occurrence and effects. Sci Total Environ 566: 333-349

Li H-X, Ma L-S, Lin L, Ni Z-X, Xu X-R, Shi H-H, Yan Y, Zheng G-M, Rittschof D (2018a) Microplastics in oysters Saccostrea cucullata along the Pearl River estuary, China. Environ Pollut 236:619-625

Li J, Liu H, Chen JP (2018b) Microplastics in freshwater systems: a review on occurrence, environmental effects, and methods for microplastics detection. Water Res 137:362-374

Li L, Xu G, Yu H, Xing J (2018c) Dynamic membrane for micro-particle removal in wastewater treatment: performance and influencing factors. Sci Total Environ 627:332-340

Liebezeit G, Liebezeit E (2013) Non-pollen particulates in honey and sugar. Food Addit Contamin A 30(12):2136-2140

Lithner D, Larsson Å, Dave G (2011) Environmental and health hazard ranking and assessment of plastic polymers based on chemical composition. Sci Total Environ 409(18):3309-3324

Liu F, Nord NB, Bester K, Vollertsen J (2020) Microplastics removal from treated wastewater by a biofilter. Water 12(4):1085

Löder MGJ, Kuczera M, Mintenig S, Lorenz C, Gerdts G (2015) Focal plane array detector-based micro-Fourier-transform infrared imaging for the analysis of microplastics in environmental samples. Environ Chem 12(5):563-581

Long Z, Pan Z, Wang W, Ren J, Yu X, Lin L, Lin H, Chen H, Jin X (2019) Microplastic abundance, characteristics, and removal in wastewater treatment plants in a coastal city of China. Water Res 155:255-265

Lusher A, Mchugh M, Thompson R (2013) Occurrence of microplastics in the gastrointestinal tract of pelagic and demersal fish from the English Channel. Mar Pollut Bull 67(1-2):94-99

Ma B, Xue W, Hu C, Liu H, Qu J, Li L (2019) Characteristics of microplastic removal via coagulation and ultrafiltration during drinking water treatment. Chem Eng J 359:159-167

Mahon AM, O'Connell B, Healy MG, O'Connor I, Officer R, Nash R, Morrison L (2017) Microplastics in sewage sludge: effects of treatment. Environ Sci Technol 51(2):810-818

Majewsky M, Bitter H, Eiche E, Horn H (2016) Determination of microplastic polyethylene (PE) and polypropylene (PP) in environmental samples using thermal analysis (TGA-DSC). Sci Total Environ 568:507-511

Mason SA, Garneau D, Sutton R, Chu Y, Ehmann K, Barnes J, Fink P, Papazissimos D, Rogers DL (2016) Microplastic pollution is widely detected in US municipal wastewater treatment plant effluent. Environ Pollut 218:1045-1054

Meeker JD, Sathyanarayana S, Swan SH (2009) Phthalates and other additives in plastics: human exposure and associated health outcomes. Philos Trans Royal Soc B Biol Sci 364(1526):2097-2113

Melzer D, Osborne NJ, Henley WE, Cipelli R, Young A, Money C, McCormack P, Luben R, Khaw K-T, Wareham NJ (2012) Urinary bisphenol A concentration and risk of future coronary artery disease in apparently healthy men and women. Circulation 125(12):14821490

Mettang T, Thomas S, Kiefer T, Fischer F-P, Kuhlmann U, Wodarz R, Retternmeier A (1996) Uraemic pruritus and exposure to di (2ethylhexyl) phthalate (DEHP) in haemodialysis patients. Nephrol Dial Transplant 11(12):2439-2443

Michielssen MR, Michielssen ER, Ni J, Duhaime MB (2016) Fate of microplastics and other small anthropogenic litter (SAL) in wastewater treatment plants depends on unit processes employed. Environ Sci Water Res Technol 2(6):1064-1073

Mintenig S, Int-Veen I, Löder MG, Primpke S, Gerdts G (2017) Identification of microplastic in effluents of waste water treatment plants using focal plane array-based micro-Fourier-transform infrared imaging. Water Res 108:365-372

Moog D, Schmitt J, Senger J, Zarzycki J, Rexer K-H, Linne U, Erb T, Maier UG (2019) Using a marine microalga as a chassis for polyethylene terephthalate (PET) degradation. Microb Cell Factories 18(1):171

Moriyama K, Tagami T, Akamizu T, Usui T, Saijo M, Kanamoto N, Hataya Y, Shimatsu A, Kuzuya H, Nakao K (2002) Thyroid hormone action is disrupted by bisphenol $\mathrm{A}$ as an antagonist. $\mathrm{J}$ Clin Endocrinol Metabol 87(11):5185-5190

Mrvčić J, Stanzer D, Šolić E, Stehlik-Tomas V (2012) Interaction of lactic acid bacteria with metal ions: opportunities for improving food safety and quality. World J Microbiol Biotechnol 28(9):2771-2782

Mühlschlegel P, Hauk A, Walter U, Sieber R (2017) Lack of evidence for microplastic contamination in honey. Food Addit Contamin A 34(11):1982-1989

Murphy F, Ewins C, Carbonnier F, Quinn B (2016) Wastewater treatment works (WwTW) as a source of microplastics in the aquatic environment. Environ Sci Technol 50(11):5800-5808

Murray F, Cowie PR (2011) Plastic contamination in the decapod crustacean Nephrops norvegicus (Linnaeus, 1758). Mar Pollut Bull 62(6): $1207-1217$

Naji A, Nuri M, Vethaak AD (2018) Microplastics contamination in molluscs from the northern part of the Persian Gulf. Environ Pollut 235:113-120

Napper IE, Thompson RC (2016) Release of synthetic microplastic plastic fibres from domestic washing machines: Effects of fabric type and washing conditions. Mar Pollut Bull 112(1-2):39-45 
Neves D, Sobral P, Ferreira JL, Pereira T (2015) Ingestion of microplastics by commercial fish off the Portuguese coast. Mar Pollut Bull 101(1):119-126

Nizzetto L, Bussi G, Futter MN, Butterfield D, Whitehead PG (2016) A theoretical assessment of microplastic transport in river catchments and their retention by soils and river sediments. Environ Sci Process Impacts 18(8):1050-1059

Nuelle M-T, Dekiff JH, Remy D, Fries E (2014) A new analytical approach for monitoring microplastics in marine sediments. Environ Pollut 184:161-169

Paço A, Duarte K, da Costa JP, Santos PS, Pereira R, Pereira M, Freitas AC, Duarte AC, Rocha-Santos TA (2017) Biodegradation of polyethylene microplastics by the marine fungus Zalerion maritimum. Sci Total Environ 586:10-15

Padervand M, Lichtfouse E, Robert D, Wang C (2020) Removal of microplastics from the environment. A review. Environ Chem Lett:1-22

Park HB, Kamcev J, Robeson LM, Elimelech M, Freeman BD (2017) Maximizing the right stuff: the trade-off between membrane permeability and selectivity. Science 356(6343):eaab0530

Pauly JL, Stegmeier SJ, Allaart HA, Cheney RT, Zhang PJ, Mayer AG, Streck RJ (1998) Inhaled cellulosic and plastic fibers found in human lung tissue. Cancer Epidemiol Prevent Biomark 7(5):419-428

Peng G, Zhu B, Yang D, Su L, Shi H, Li D (2017) Microplastics in sediments of the Changjiang Estuary, China. Environ Pollut 225: 283-290

Perren W, Wojtasik A, Cai Q (2018) Removal of microbeads from wastewater using electrocoagulation. ACS Omega 3(3):3357-3364

Poerio T, Piacentini E, Mazzei R (2019) Membrane processes for microplastic removal. Molecules 24(22):4148

Rani M, Shim WJ, Han GM, Jang M, Al-Odaini NA, Song YK, Hong SH (2015) Qualitative analysis of additives in plastic marine debris and its new products. Arch Environ Contam Toxicol 69(3):352-366

Rocha-Santos T, Duarte AC (2015) A critical overview of the analytical approaches to the occurrence, the fate and the behavior of microplastics in the environment. TrAC Trends Anal Chem 65: 47-53

Rochman CM, Tahir A, Williams SL, Baxa DV, Lam R, Miller JT, Teh F-C, Werorilangi S, Teh SJ (2015) Anthropogenic debris in seafood: Plastic debris and fibers from textiles in fish and bivalves sold for human consumption. Sci Rep 5:14340

Ropero A, Alonso-Magdalena P, Garcia-Garcia E, Ripoll C, Fuentes E, Nadal A (2008) Bisphenol-A disruption of the endocrine pancreas and blood glucose homeostasis. Int J Androl 31(2):194-200

Rummel CD, Löder MG, Fricke NF, Lang T, Griebeler E-M, Janke M, Gerdts $G$ (2016) Plastic ingestion by pelagic and demersal fish from the North Sea and Baltic Sea. Mar Pollut Bull 102(1):134-141

Russell JR, Huang J, Anand P, Kucera K, Sandoval AG, Dantzler KW, Hickman D, Jee J, Kimovec FM, Koppstein D (2011) Biodegradation of polyester polyurethane by endophytic fungi. Appl Environ Microbiol 77(17):6076-6084

Schymanski D, Goldbeck C, Humpf H-U, Fürst P (2018) Analysis of microplastics in water by micro-Raman spectroscopy: release of plastic particles from different packaging into mineral water. Water Res 129:154-162

Seo H, Kim S, Son HF, Sagong H-Y, Joo S, Kim K-J (2019) Production of extracellular PETase from Ideonella sakaiensis using secdependent signal peptides in E. coli. Biochem Biophys Res Commun 508(1):250-255

Shabbir S, Faheem M, Ali N, Kerr PG, Wang L-F, Kuppusamy S, Li Y (2020) Periphytic biofilm: an innovative approach for biodegradation of microplastics. Sci Total Environ 717:137064

Shah AA, Hasan F, Hameed A, Ahmed S (2008) Biological degradation of plastics: a comprehensive review. Biotechnol Adv 26(3):246-265
Shen M, Song B, Zhu Y, Zeng G, Zhang Y, Yang Y, Wen X, Chen M, Yi H (2020) Removal of microplastics via drinking water treatment: current knowledge and future directions. Chemosphere 126612

Shim WJ, Hong SH, Eo SE (2017) Identification methods in microplastic analysis: a review. Anal Methods 9(9):1384-1391

Siegfried M, Koelmans AA, Besseling E, Kroeze C (2017) Export of microplastics from land to sea. A modelling approach. Water Res 127:249-257

Sierra I, Chialanza MR, Faccio R, Carrizo D, Fornaro L, Pérez-Parada A (2020) Identification of microplastics in wastewater samples by means of polarized light optical microscopy. Environ Sci Pollut Res 27(7):7409-7419

Silva-Cavalcanti JS, Silva JDB, de França EJ, de Araújo MCB, Gusmao F (2017) Microplastics ingestion by a common tropical freshwater fishing resource. Environ Pollut 221:218-226

Simon M, van Alst N, Vollertsen J (2018) Quantification of microplastic mass and removal rates at wastewater treatment plants applying focal plane array (FPA)-based Fourier transform infrared (FT-IR) imaging. Water Res 142:1-9

Srivastava R, Godara S (2017) Use of polycarbonate plastic products and human health. Int J Basic Clin Pharmacol 2(1):12-17

Su L, Xue Y, Li L, Yang D, Kolandhasamy P, Li D, Shi H (2016) Microplastics in taihu lake, China. Environ Pollut 216:711-719

Su L, Cai H, Kolandhasamy P, Wu C, Rochman CM, Shi H (2018) Using the Asian clam as an indicator of microplastic pollution in freshwater ecosystems. Environ Pollut 234:347-355

Suaria G, Achtypi A, Perold V, Lee JR, Pierucci A, Bornman TG, Aliani S, Ryan PG (2020) Microfibers in oceanic surface waters: a global characterization. Sci Adv 6(23):eaay8493

Sun J, Dai X, Wang Q, van Loosdrecht MC, Ni B-J (2019) Microplastics in wastewater treatment plants: detection, occurrence and removal. Water Res 152:21-37

Sun C, Wang Z, Chen L, Li F (2020) Fabrication of robust and compressive chitin and graphene oxide sponges for removal of microplastics with different functional groups. Chem Eng J 124796

Sundbæk KB, Koch IDW, Villaro CG, Rasmussen NS, Holdt SL, Hartmann NB (2018) Sorption of fluorescent polystyrene microplastic particles to edible seaweed Fucus vesiculosus. J Appl Phycol 30(5):2923-2927

Talvitie J, Mikola A, Koistinen A, Setälä O (2017a) Solutions to microplastic pollution-removal of microplastics from wastewater effluent with advanced wastewater treatment technologies. Water Res 123:401-407

Talvitie J, Mikola A, Setälä O, Heinonen M, Koistinen A (2017b) How well is microlitter purified from wastewater?-A detailed study on the stepwise removal of microlitter in a tertiary level wastewater treatment plant. Water Res 109:164-172

Tanaka K, Takada H (2016) Microplastic fragments and microbeads in digestive tracts of planktivorous fish from urban coastal waters. Sci Rep 6:34351

Thompson RC, Olsen Y, Mitchell RP, Davis A, Rowland SJ, John AW, McGonigle D, Russell AE (2004) Lost at sea: where is all the plastic? Science 304(5672):838-838

Triebskorn R, Braunbeck T, Grummt T, Hanslik L, Huppertsberg S, Jekel M, Knepper TP, Krais S, Müller YK, Pittroff M (2019) Relevance of nano-and microplastics for freshwater ecosystems: a critical review. TrAC Trends Anal Chem 110:375-392

Tsukame T, Ehara Y, Shimizu Y, Kutsuzawa M, Saitoh H, Shibasaki Y (1997) Characterization of microstructure of polyethylenes by differential scanning calorimetry. Thermochim Acta 299(1-2):27-32

Van Cauwenberghe L, Vanreusel A, Mees J, Janssen CR (2013) Microplastic pollution in deep-sea sediments. Environ Pollut 182: 495-499

Van Franeker JA, Blaize C, Danielsen J, Fairclough K, Gollan J, Guse N, Hansen P-L, Heubeck M, Jensen J-K, Le Guillou G (2011) 
Monitoring plastic ingestion by the northern fulmar Fulmarus glacialis in the North Sea. Environ Pollut 159(10):2609-2615

Vethaak AD, Leslie HA (2016) Plastic debris is a human health issue. Environ Sci Technol 50(13):6825-6826

Vimala P, Mathew L (2016) Biodegradation of polyethylene using Bacillus subtilis. Procedia Technol 24:232-239

Von Moos N, Burkhardt-Holm P, Köhler A (2012) Uptake and effects of microplastics on cells and tissue of the blue mussel Mytilus edulis L. after an experimental exposure. Environ Sci Technol 46(20):1132711335

Wang J, Tan Z, Peng J, Qiu Q, Li M (2016) The behaviors of microplastics in the marine environment. Mar Environ Res 113:717

Wang J, Peng J, Tan Z, Gao Y, Zhan Z, Chen Q, Cai L (2017a) Microplastics in the surface sediments from the Beijiang River littoral zone: composition, abundance, surface textures and interaction with heavy metals. Chemosphere 171:248-258

Wang W, Ndungu AW, Li Z, Wang J (2017b) Microplastics pollution in inland freshwaters of China: a case study in urban surface waters of Wuhan, China. Sci Total Environ 575:1369-1374

Wang L, Kaeppler A, Fischer D, Simmchen J (2019) Photocatalytic TiO2 micromotors for removal of microplastics and suspended matter. ACS Appl Mater Interfaces 11(36):32937-32944

Welden NA, Cowie PR (2017) Degradation of common polymer ropes in a sublittoral marine environment. Mar Pollut Bull 118(1-2):248-253

Woodall LC, Sanchez-Vidal A, Canals M, Paterson GL, Coppock R, Sleight V, Calafat A, Rogers AD, Narayanaswamy BE, Thompson $\mathrm{RC}$ (2014) The deep sea is a major sink for microplastic debris. $\mathrm{R}$ Soc Open Sci 1(4):140317

Wright SL, Kelly FJ (2017) Plastic and human health: a micro issue? Environ Sci Technol 51(12):6634-6647

Wright SL, Thompson RC, Galloway TS (2013) The physical impacts of microplastics on marine organisms: a review. Environ Pollut 178: 483-492

Yamada-Onodera K, Mukumoto H, Katsuyaya Y, Saiganji A, Tani Y (2001) Degradation of polyethylene by a fungus, Penicillium simplicissimum YK. Polym Degrad Stab 72(2):323-327

Yamashita R, Takada H, Fukuwaka M-a, Watanuki Y (2011) Physical and chemical effects of ingested plastic debris on short-tailed shearwaters, Puffinus tenuirostris, in the North Pacific Ocean. Mar Pollut Bull 62(12):2845-2849

Yang D, Shi H, Li L, Li J, Jabeen K, Kolandhasamy P (2015a) Microplastic pollution in table salts from China. Environ Sci Technol 49(22):13622-13627

Yang Y, Yang J, Wu W-M, Zhao J, Song Y, Gao L, Yang R, Jiang L (2015b) Biodegradation and mineralization of polystyrene by plastic-eating mealworms: part 2. Role of gut microorganisms. Environ Sci Technol 49(20):12087-12093

Yoshida S, Hiraga K, Takehana T, Taniguchi I, Yamaji H, Maeda Y, Toyohara K, Miyamoto K, Kimura Y, Oda K (2016) A bacterium that degrades and assimilates poly (ethylene terephthalate). Science 351(6278):1196-1199

Yu J, Wang P, Ni F, Cizdziel J, Wu D, Zhao Q, Zhou Y (2019) Characterization of microplastics in environment by thermal gravimetric analysis coupled with Fourier transform infrared spectroscopy. Mar Pollut Bull 145:153-160

Zhang K, Gong W, Lv J, Xiong X, Wu C (2015) Accumulation of floating microplastics behind the Three Gorges Dam. Environ Pollut 204:117-123

Zhang K, Su J, Xiong X, Wu X, Wu C, Liu J (2016) Microplastic pollution of lakeshore sediments from remote lakes in Tibet plateau, China. Environ Pollut 219:450-455

Zhang K, Xiong X, Hu H, Wu C, Bi Y, Wu Y, Zhou B, Lam PK, Liu J (2017) Occurrence and characteristics of microplastic pollution in Xiangxi Bay of Three Gorges Reservoir, China. Environ Sci Technol 51(7):3794-3801

Zhang K, Shi H, Peng J, Wang Y, Xiong X, Wu C, Lam PK (2018) Microplastic pollution in China's inland water systems: a review of findings, methods, characteristics, effects, and management. Sci Total Environ 630:1641-1653

Zhang J, Gao D, Li Q, Zhao Y, Li L, Lin H, Bi Q, Zhao Y (2020) Biodegradation of polyethylene microplastic particles by the fungus Aspergillus flavus from the guts of wax moth Galleria mellonella. Sci Total Environ 704:135931

Zhao S, Zhu L, Wang T, Li D (2014) Suspended microplastics in the surface water of the Yangtze Estuary System, China: first observations on occurrence, distribution. Mar Pollut Bull 86(1-2):562-568

Zhao S, Zhu L, Li D (2015) Microplastic in three urban estuaries, China. Environ Pollut 206:597-604

Zhao S, Zhu L, Li D (2016) Microscopic anthropogenic litter in terrestrial birds from Shanghai, China: not only plastics but also natural fibers. Sci Total Environ 550:1110-1115

Ziajahromi S, Neale PA, Rintoul L, Leusch FD (2017) Wastewater treatment plants as a pathway for microplastics: development of a new approach to sample wastewater-based microplastics. Water Res 112: 93-99

Zitko V, Hanlon M (1991) Another source of pollution by plastics: skin cleaners with plastic scrubbers. Mar Pollut Bull 22(1):41-42

Publisher's note Springer Nature remains neutral with regard to jurisdictional claims in published maps and institutional affiliations. 